\title{
Simulated or measured soil moisture: which one is adding more value to regional landslide early warning?
}

\author{
Adrian Wicki ${ }^{1}$, Per-Erik Jansson ${ }^{2}$, Peter Lehmann ${ }^{3}$, Christian Hauck ${ }^{4}$, and Manfred Stähli ${ }^{1}$ \\ ${ }^{1}$ Mountain Hydrology and Mass Movements Research Unit, Swiss Federal Institute for Forest, Snow and Landscape Research \\ WSL, Zürcherstrasse 111, 8903 Birmensdorf, Switzerland \\ ${ }^{2}$ Department of Land and Water Resources Engineering, KTH Royal Institute of Technology, 10044 Stockholm, Sweden \\ ${ }^{3}$ Institute of Terrestrial Ecosystems, ETH Zurich, Universitätstrasse 16, 8092 Zürich, Switzerland \\ ${ }^{4}$ Department of Geosciences, University of Fribourg, Chemin du Musée 4, 1700 Fribourg, Switzerland
}

Correspondence: Adrian Wicki (adrian.wicki@wsl.ch)

Received: 5 March 2021 - Discussion started: 15 March 2021

Revised: 3 August 2021 - Accepted: 3 August 2021 - Published: 26 August 2021

\begin{abstract}
The inclusion of soil wetness information in empirical landslide prediction models was shown to improve the forecast goodness of regional landslide early warning systems (LEWSs). However, it is still unclear which source of information - numerical models or in situ measurements - is of higher value for this purpose. In this study, soil moisture dynamics at 133 grassland sites in Switzerland were simulated for the period of 1981 to 2019, using a physically based 1D soil moisture transfer model. A common parameterization set was defined for all sites, except for site-specific soil hydrological properties, and the model performance was assessed at a subset of 14 sites where in situ soil moisture measurements were available on the same plot. A previously developed statistical framework was applied to fit an empirical landslide forecast model, and receiver operating characteristic analysis (ROC) was used to assess the forecast goodness. To assess the sensitivity of the landslide forecasts, the statistical framework was applied to different model parameterizations, to various distances between simulation sites and landslides and to measured soil moisture from a subset of 35 sites for comparison with a measurement-based forecast model. We found that (i) simulated soil moisture is a skilful predictor for regional landslide activity, (ii) that it is sensitive to the formulation of the upper and lower boundary conditions, and (iii) that the information content is strongly distance dependent. Compared to a measurement-based landslide forecast model, the model-based forecast performs better as the homogenization of hydrological processes, and the site representation can lead to a better representation of trig-
\end{abstract}

gering event conditions. However, it is limited in reproducing critical antecedent saturation conditions due to an inadequate representation of the long-term water storage.

\section{Introduction}

Landslides are a major natural hazard causing fatalities and damage in mountainous regions worldwide (Froude and Petley, 2018). The term "landslide" includes various types of mass movements spanning over different source materials (e.g. soil and rock), process dynamics (e.g. slide, flow and fall) and trigger types (e.g. water infiltration, earthquakes and human interaction; Hungr et al., 2014; Varnes, 1978; Wieczorek, 1996). Here, we focus on rainfalland snowmelt-triggered shallow landslides which occur frequently in Switzerland (Hess et al., 2014). The landslide process can be analysed by "cause" and "trigger" factors (Bogaard and Greco, 2016). Factors that precondition the slope to sliding (cause factors) include the long-term weathering of the slope material, the topographic disposition, the characteristics of the vegetation cover and the hydrological prewetting of the slope. The eventual failure of a slope along a shear plane is connected to a local and short-duration decrease in shear strength (trigger factors) due to pore water pressure increase from direct rainfall or snowmelt water infiltration or due to the indirect build-up of a perched water table or groundwater (GW) table (Bogaard and Greco, 2016; Terlien, 1998; Terzaghi, 1943). 
Risk awareness and the corresponding response of people is a significant factor for mortality, particularly during shallow landslide events (Pollock and Wartman, 2020). In this respect, landslide early warning systems (LEWSs), which allow the prediction of the landslide hazard, have become an essential part of risk management in many places around the world (e.g. Baum et al., 2010; Guzzetti et al., 2020; Stähli et al., 2015). Regional LEWSs, also referred to as territorial (Piciullo et al., 2018) or geographical (Guzzetti et al., 2020) LEWSs, make predictions for multiple landslides and operate at the regional to national scale. Statistical landslide forecast models relate environmental variables, such as rainfall characteristics or soil wetness variation, to the occurrence of landslides. They are fundamentally based on the time series of environmental data and a comprehensive landslide inventory (Guzzetti et al., 2020; Terlien, 1998).

In the past, many regional LEWSs have been based on statistical forecast models that describe empirical relationships between rainfall events and landslide occurrence (Caine, 1980; Guzzetti et al., 2008; Segoni et al., 2018a). While this approach benefits from widely available rainfall data, the focus on triggering factors disregards the influence of the antecedent wetness conditions (cause factors), which could be represented by including soil wetness information (Bogaard and Greco, 2018). In fact, forecast goodness improvement was reported after the incorporation of in situ soil moisture measurements (Mirus et al., 2018a, b; Thomas et al., 2020), remotely sensed soil moisture (Bordoni et al., 2020; Brocca et al., 2016; Thomas et al., 2019; Zhao et al., 2019a; Zhuo et al., 2019b) or simulated soil moisture using physically based models (e.g. Ponziani et al., 2012; Segoni et al., 2018b; Zhuo et al., 2019a). Other landslide forecast models exist that express antecedent wetness conditions in terms of accumulated pre-event precipitation (e.g. Aleotti, 2004; Martelloni et al., 2012), or antecedent soil wetness or precipitation indices (e.g. Crozier, 1999; Glade, 2000; Godt et al., 2006).

At the point scale, in situ soil moisture sensors (time and frequency domain reflectometry, i.e. TDR and FDR, respectively, or capacitance based) estimate dielectric permittivity (Babaeian et al., 2019) from which soil moisture is deduced, using an empirical calibration function (e.g. the equation of Topp et al., 1980). They are representative for a specific volume of soil and are usually integrated to depth profiles. While sensor networks deliver soil moisture estimates at high temporal resolution, installation and long-term maintenance are costly and difficult, and the representativeness for regional landslide activity decreases significantly with distance from the soil moisture site (Wicki et al., 2020). Larger spatial integration is achieved by using remotely sensed soil moisture information derived from microwave emissions (Reichle et al., 2017). However, the spatial and temporal resolution are coarse and the sensing depth is shallow, limiting the potential for LEWS applications in mountainous regions (Thomas et al., 2019; Zhuo et al., 2019a).
Numerical models for the simulation of soil water dynamics may help in this regard as they provide cheap, continuous and spatially and temporally consistent soil moisture estimates. Such models typically simulate the accumulation and redistribution of water (and heat) either in specific soil profiles (in one dimension) or for larger areas (pixels or hydrological response units) for time resolutions from minutes to days. Physically based models explicitly represent hydrologic state variables and fluxes by mathematical formulations (Fatichi et al., 2016), where the variably saturated water flow is often described by the Richards' equation (1931), and the mathematical expressions in the form of partial differential equations are solved with a numerical method (Feddes et al., 1988). In comparison to simpler conceptual or bucket models, physically based models are more time-consuming in calculation and require more parameter settings. However, they are less dependent on specific calibration procedures, since parameter values can be constrained by observable quantities or expert decisions (Gharari et al., 2014; Gupta and Nearing, 2014), or they can be inferred from easily measured quantities by means of pedotransfer functions (Van Looy et al., 2017; Schaap et al., 2001). The one-dimensional coupled water and heat transfer models go back to the pioneering work of Harlan (1973) and were further developed and implemented in computer codes for example by Van Genuchten (WORM, 1987), Jansson (CoupModel, 2012) or Šimůnek et al. (Hydrus-1D, 2012). The two-dimensional soil hydrological models, such as PREVAH (Viviroli et al., 2009), WaSiM-ETH (Klok et al., 2001), TOPKAPI (TOPographic Kinematic APproximation and Integration; Liu and Todini, 2002) or Tethys-Chloris (Fatichi et al., 2012), to name a few, are typically applied at catchment or regional scale. Due to the larger coverage, they are restricted by computational resources and often have to simplify the modelling process (e.g. by reducing the temporal resolution or the number of modelling layers or the number of processes represented), but they have the advantage of lateral connectivity and basinwide coverage (Fatichi et al., 2016). Common limitations of all physically based models are mainly related to the availability of appropriate soil physical properties to describe the soil hydraulic characteristics, simplifications of the model boundary conditions and the mathematical description of the hydrological processes, and the quality of the dynamic input data (Feddes et al., 1988; Paniconi and Putti, 2015).

Ultimately, the question arises to what extent landslide forecast models that are based on simulated soil moisture are reliable and representative in comparison to models based on actual soil moisture measurements. In this study, we aim (i) to clarify the skill of a LEWS based on simulated soil moisture from a 1D soil moisture model compared to one based on in situ soil moisture measurements, (ii) to assess the sensitivity of this skill to model assumptions and parameters and (iii) to evaluate the potential of extending a measurement-based LEWSs to sites with no soil moisture measurements. This study assesses the potential and limita- 
tions of using a 1D soil water transfer model for regional landslide early warning and highlights the strengths and weaknesses compared to using soil moisture measurements. We use plot-scale soil hydrological simulations to be able to directly compare the results to a landslide forecast model based on in situ soil moisture measurements.

\section{Material and methods}

\subsection{Study design}

The following section summarizes the design of this study. In a first step, soil moisture was simulated at 133 sites in Switzerland using a 1D soil moisture transfer model. Second, the forecast goodness for regional landslide activity was assessed by fitting and evaluating a statistical landslide forecast model to observed shallow landslides. Finally, the landslide forecast goodness was compared with a landslide forecast model based on in situ soil moisture measurements available at a subset of the modelled sites. We applied a statistical framework previously developed to assess the information content of in situ soil wetness information for regional landslide activity (Wicki et al., 2020), and we used the same soil moisture monitoring data set compiled in the named study for comparison with a measurement-based forecast model. We focused on 1D soil moisture modelling because these models permit high temporal resolution, detailed depth integration and a good representation of physical infiltration processes, while still meeting the computational restraints.

\subsection{Study area}

The study area covers the entire country of Switzerland (Fig. 1) and, thus, an area of approximately $41300 \mathrm{~km}^{2}$. The climate in Switzerland transitions from an oceanic (wet) climate in the west to a more continental (dry) climate in the east of the country, and the presence of the Alps strongly impacts the regional weather patterns. Hence, yearly precipitation amounts are highly variable and range from less than $600 \mathrm{~mm}$ in some inner alpine valleys to more than $3000 \mathrm{~mm}$ at high altitudes in the Alps. Precipitation falls throughout the year, with peaks during the summer months in most regions, whereas the fraction of snow strongly depends on the altitude (CH2018, 2018). Yearly evapotranspiration is highest in lowlands (up to $600 \mathrm{~mm}$ over grasslands) and continuously decreases to less than $250 \mathrm{~mm}$ at elevations higher than $2500 \mathrm{~m}$ a.s.1. (Menzel et al., 1999).

Landslides in Switzerland occur mostly along the northern pre-Alps and south of the Alps (Ticino) due to the presence of susceptible geological formations (flysch, schist or Bündner schist and phyllite), thick soil and debris covers $n$ the moderately steep hillslopes and the occurrence of intense rainfall events (Schmid et al., 2004). Most landslides occur during the summer months due to short-term thunderstorm cells or long-standing precipitation events often caused by impinge- ment of moist air masses on the Alps (CH2018, 2018; Hess et al., 2014; Hilker et al., 2009).

\subsection{Soil moisture model}

In this study, the heat and mass transfer model CoupModel (Jansson, 2012) was used to simulate soil water transfer along a 1D virtual soil profile. The CoupModel has been used extensively to simulate temporal soil moisture dynamics (e.g. Okkonen et al., 2017; Pellet et al., 2016; Scherler et al., 2010; Wu et al., 2020; Wu and Jansson, 2013) and soil water balance variations (e.g. Christiansen et al., 2006; Madani et al., 2018; Walthert et al., 2015). In the context of landslide early warning, parts of the CoupModel were used for soil moisture simulations within the Norwegian national forecasting service for predicting rainfall-induced landslides (Krøgli et al., 2018).

At the core of the model, two coupled differential equations for water and heat transport are solved, assuming that flows are the result of gradients (Jansson and Karlberg, 2011). The soil water flow, $q_{\mathrm{w}}$, follows Darcy's law as generalized for unsaturated flow by Buckingham (1907).

$q_{\mathrm{w}}=-K_{\mathrm{w}}\left(\frac{\delta \psi}{\delta z}-1\right)$

where $K_{\mathrm{w}}$ is the unsaturated hydraulic conductivity, $\psi$ is the matric potential head, and $z$ is the depth. Formulations to simulate vapour flow and bypass flow in macropores are implemented in the CoupModel as well but were not included in this study.

From Eq. (1) and the law of mass conservation, the unsaturated water flow equation follows:

$\frac{\partial \theta}{\partial t}=-\frac{\partial q_{\mathrm{w}}}{\partial z}+s_{\mathrm{w}}$

where $\theta$ is the soil water content, and $s_{\mathrm{W}}$ is a source or sink term.

To solve the water flow equation, two soil characteristic hydraulic properties need to be defined for each model layer, both of which are considered to be functions of the water content, i.e. the soil water retention curve, characterizing the relationship between matric potential and water content, the unsaturated hydraulic conductivity function, describing the hydraulic conductivity as a function of water saturation (or matric potential), and the saturated soil hydraulic conductivity. In this study, they were defined by the Mualem and Van Genuchten closed-form equations (Van Genuchten, 1980; Mualem, 1976) as follows:

$$
\begin{aligned}
& \theta=\theta_{\mathrm{r}}+\frac{\theta_{\mathrm{s}}-\theta_{\mathrm{r}}}{\left[1+(\alpha \psi)^{n}\right]^{m}}, \\
& K_{\mathrm{w}}=K_{\mathrm{s}} \frac{\left(1-(\alpha \psi)^{n-1}\left(1+(\alpha \psi)^{n}\right)^{-m}\right)^{2}}{\left(1+(\alpha \psi)^{n}\right)^{\frac{m}{2}}},
\end{aligned}
$$




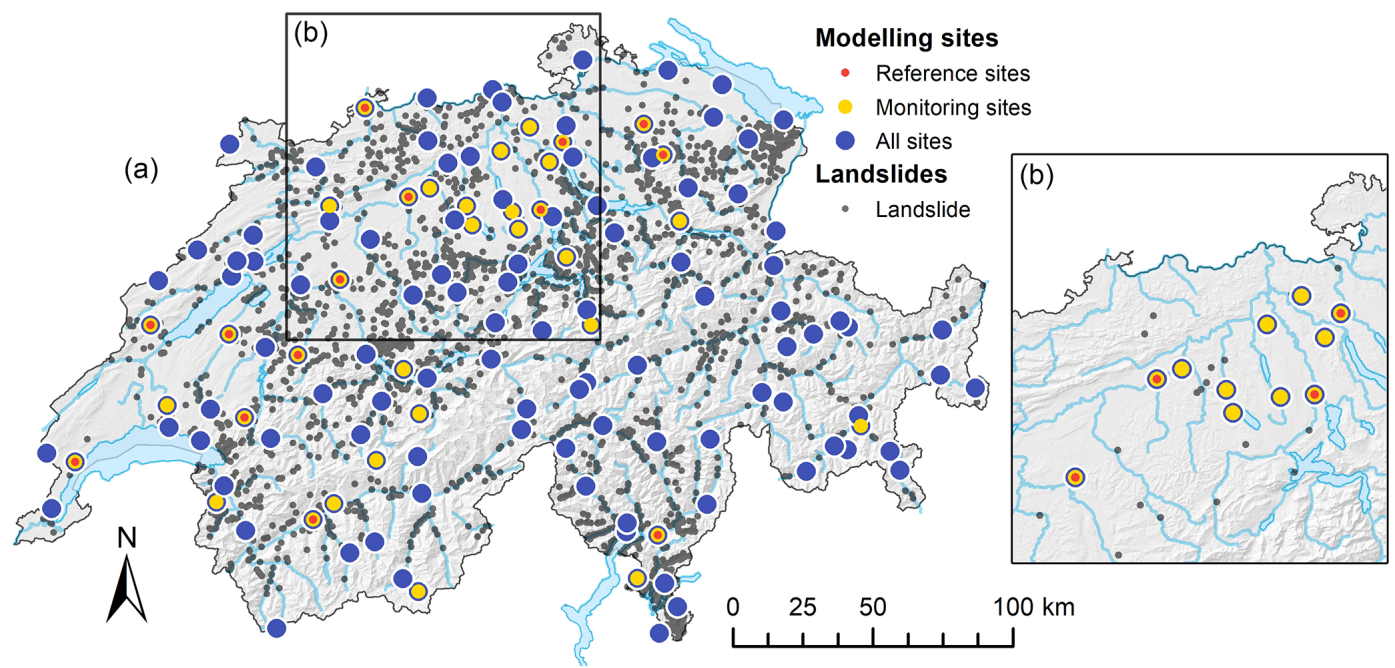

Figure 1. Map of Switzerland showing the locations of the soil moisture modelling sites (coloured points) and the landslide locations (black points), including (a) all sites and all landslides of the entire study period from 1981 to 2019 and (b) a subset of sites and landslides that were triggered during a series of rainfall events between 30 April and 3 May 2005.

where $\theta_{\mathrm{r}}$ is the residual water content, $\theta_{\mathrm{S}}$ is saturated water content (equal to porosity), $\alpha, n$ and $m=1-(1 / n)$ are empirical parameters, and $K_{\mathrm{S}}$ is the saturated hydraulic conductivity. The heat flow equation follows Fourier's law and accounts for conduction and convection of heat (Appendix A). The differential equations are solved with a finite difference method (Euler integration), which requires a soil profile with a discrete number of layers having homogenous soil properties (Jansson and Karlberg, 2011).

In the following, all other main processes represented in the CoupModel set-up are described. For a detailed description of the associated mathematical expressions, see Appendix A. At the lower boundary, water may leave the soil column by deep percolation. In the present study, two different lower boundary conditions were applied; the first boundary condition assumes a nonsaturated soil profile. If a predefined pressure head is surpassed in the lowest layer, outflow occurs as a function of the hydraulic conductivity (free drainage), whereas no flow occurs if the pressure head is below the specified limit. The second boundary condition may represent saturated conditions and a variable groundwater table. Here, outflow is calculated with a seepage equation dependent on the depth and spacing distance to a drain (Jansson and Karlberg, 2011).

Infiltration capacity governs the infiltration of water at the upper boundary, and it is a function of the top-most layer's saturated hydraulic conductivity and the pressure gradient to the surface. If the infiltration rate is exceeded by the water available for infiltration, or if over-saturation leads to an upward movement of the soil water, water may run off laterally. Water loss by evapotranspiration consists of bare soil evaporation and vegetation transpiration, which, in the present study, was a mowed lawn. The individual evapotran- spiration components were calculated using the PenmanMonteith equation (Monteith, 1965), which is mainly governed by aerodynamic and surface resistances (evaporation), as well as stomatal resistance (transpiration). The potential transpiration is limited by the availability of soil water within the rooting depth of the plants and is reduced by low ground temperatures. Finally, a snow cover may be built up based on the air temperature at times of precipitation. Snowmelt and refreezing were calculated with an empirical function depending on air temperature, global radiation and surface heat flow (Jansson and Karlberg, 2011).

\subsection{Model set-up and parameterization}

Soil moisture was simulated at 133 sites in Switzerland where meteorological data was available from an on-site or nearby meteorological station, and each site was parameterized as a grassland location (all sites; Fig. 1a; Table 1). At a subset of 35 sites (monitoring sites), in situ soil moisture measurements were available, which were used for benchmarking the statistical landslide forecast model (see Sect. 2.6). At a subset of 14 selected sites (reference sites), in situ soil moisture measurements were used to assess the soil moisture simulations from the CoupModel. They were selected because they were located on the same plot as the meteorological station and below grassland vegetation, i.e. the soil moisture sites which were disregarded for model assessment were located at far distance from the meteorological site $(>2 \mathrm{~km})$ and/or located in a forest and, thus, not representative for the grassland parameterization.

The goal of this study was to define a common parameterization set for all sites (i.e. no site-specific calibration was conducted) to be able to apply the model at sites where 
Table 1. Sets of sites, available data sets and number of sites.

\begin{tabular}{|c|c|c|c|c|}
\hline \multirow[t]{2}{*}{ Sites set } & \multicolumn{2}{|c|}{ Texture and bulk density information } & \multirow[t]{2}{*}{ Co-located soil moisture measurements } & \multirow[t]{2}{*}{$N$ sites } \\
\hline & SoilGrids & Soil samples & & \\
\hline All sites & Yes & No & No & 133 \\
\hline Monitoring sites & Yes & Yes & Yes & 35 \\
\hline Reference sites & Yes & Yes & Yes (grassland only at $<2 \mathrm{~km}$ distance) & 14 \\
\hline
\end{tabular}

no site-specific calibration is possible because soil moisture measurements are missing. Most parameter values were left at the default values of the CoupModel (documented in detail by Jansson and Karlberg, 2011), whereas others were (i) adjusted to fit observed soil moisture dynamics, (ii) were taken from literature values or (iii) were defined at the author's discretion. A description of the key parameters and chosen values are given in Appendix A. The plant properties for the grassland cover were defined by the literature values (leaf area index $=0.6 \mathrm{~m}^{2} \mathrm{~m}^{-2}$; canopy height $=0.25 \mathrm{~m}$; maximum root depth $=0.6 \mathrm{~m}$ ), and they were defined as homogenous throughout the season. The values for the maximal conductance of fully open stomata $\left(g_{\max }=0.03 \mathrm{~m} \mathrm{~s}^{-1}\right)$ and the critical pressure head for reduction of potential water uptake $\left(\psi_{\mathrm{c}}=1500 \mathrm{~cm}\right.$ water $)$ were chosen by comparison with observed soil moisture variation. Seasonal snow cover dynamics were compared with snow depth measurements available at some of the sites and tuned by adjusting the empirical snowmelt coefficients $\left(m_{T}=1.5 \mathrm{~kg}^{\circ} \mathrm{C}^{-1} \mathrm{~m}^{-2} \mathrm{~d}^{-1} ; m_{\mathrm{f}}=\right.$ $\left.0.1 \mathrm{~m}^{-1}, m_{\mathrm{Rmin}}=1.5 e-8 \mathrm{~kg} \mathrm{~J}^{-1}\right)$. Different lower boundary conditions were tested, including both saturated and unsaturated conditions, and best parameter values $\left(\psi_{\text {Max }}=10 \mathrm{~cm}\right.$ for unsaturated conditions; $z_{p 2}=7.5 \mathrm{~m}$ and $d_{p 2}=100 \mathrm{~m}$ for saturated conditions) were defined by comparison with observed soil moisture variation.

Soil profiles were defined by 11 model layers of increasing thickness with depth and a total thickness of $300 \mathrm{~cm}$. To reflect regional geological differences, soil hydraulic properties were varied for each site. Since no laboratory or field data were available to measure or fit the soil hydraulic parameters $\left(\alpha, n, \theta_{\mathrm{r}}, \theta_{\mathrm{s}}\right.$ and $\left.K_{\mathrm{s}}\right)$, they were predicted from easier available soil texture and bulk density values using the Rosetta3 H3w pedotransfer function (Zhang and Schaap, 2017). Rosetta 3 was derived from a data set containing 2134 soil samples from North America and Europe (Schaap et al., 2001). The underlying data set also includes data from Switzerland, giving confidence that the pedotransfer function is suitable for the application to soils in Switzerland. The required soil texture and bulk density values were derived from two sources. (1) At the 35 monitoring sites, texture and bulk density measurements were available from soil samples taken at various depths along the soil profiles where soil moisture sensors were installed (referred to as soil samples). The data were provided by the operators of the soil moisture monitoring sites (see Sect. 2.6). (2) At all 133 sites, texture and bulk density estimates were extracted from the SoilGrids system (referred to as SoilGrids), which provides global predictions of various soil properties based on machine learning techniques (Hengl et al., 2017). SoilGrids is available in $250 \mathrm{~m}$ resolution at seven standard depths $(0,5$, $15,30,60,100$ and $200 \mathrm{~cm}$ ) and permits estimates of texture and bulk density on a global scale. Comparison of the texture split values between the soil samples and SoilGrids data sets for the 35 common monitoring sites and two depth bands $(0.0-0.4 \mathrm{~m}$ and $0.4-1.0 \mathrm{~m})$ reveals a narrower value distribution of SoilGrids with particularly coarse fractions missing (Fig. 2a, e).

To further test the model sensitivity to the soil hydraulic properties, four soil profiles with uniform texture (referred to as uniform texture profiles) were defined, and soil hydraulic properties were defined based on the literature values. The profiles include homogeneous parameter values at all depths and correspond to extreme and typical coarse- and fine-grained soils. If the derived soil hydrological properties are compared between all sources, a narrower value distribution is again visible for the SoilGrids data set compared to the soil samples; however, median values are similar or of the same order of magnitude (Fig. 2b-d, f-h). Parameter values of the four uniform texture profiles vary considerably, whereas the normal, fine-grained uniform texture profile shows similar parameter values o the median values derived from the soil samples and SoilGrids.

\subsection{Meteorological input data}

The CoupModel was run at hourly time steps, using measurements of the five properties precipitation, air temperature, wind speed, relative humidity and global radiation. Data were available from meteorological stations of various monitoring networks. (1) SwissMetNet is the automatic monitoring network of the national meteorological agency MeteoSwiss. Data from 114 monitoring sites were used in this study dating back up to 1981. (2) DTN (formerly MeteoGroup) is a provider of meteorological measurements and a partner network of MeteoSwiss, and two sites were included in this study (https://www.dtn.com, last access: 16 February 2021). (3) The Long-Term Forest Ecosystem Research Programme (LWF) of the Swiss Federal Research Institute WSL conducts research on forest ecosystem processes on forested monitoring plots in Switzer- 


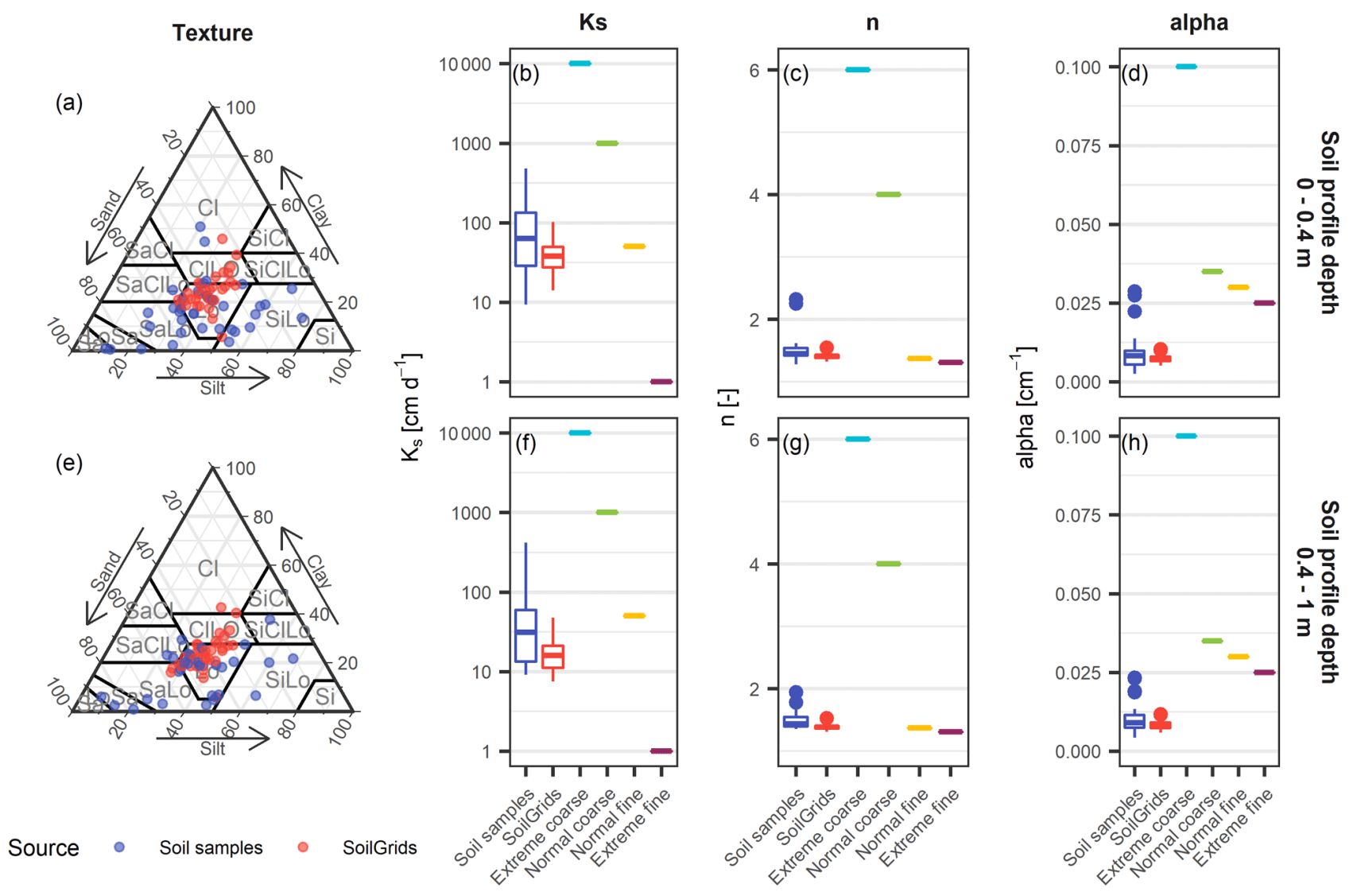

Figure 2. Soil texture splits (a, e) and soil hydraulic properties $K_{\mathrm{S}}$ (saturated hydraulic conductivity), $n$ (Van Genuchten coefficient) and $\alpha$ (Van Genuchten coefficient) (b-d, f-h) of the 35 monitoring sites averaged for the model layers in $0-40 \mathrm{~cm}(\mathbf{a}-\mathbf{d})$ and $40-100 \mathrm{~cm}$ depth (e-h). The point and box plot colours indicate different sources of information (soil samples, SoilGrids and uniform texture profiles).

land and Europe. At 14 sites, of which eight were included in this study, co-located meteorological measurements are taken in an open-field at less than $2 \mathrm{~km}$ distance from the plots (Rebetez et al., 2018). (4) The Swiss FluxNet initiative includes eight long-term ecosystem sites with eddy covariance flux measurements in Switzerland (http://www.swissfluxnet.ch/, last access: 16 February 2021). In this study, meteorological measurements from two sites were included. (5) Finally, meteorological measurements from one site at the Rietholzbach research catchment were included, which is operated by the Land-Climate Dynamics Group (ETH Zurich; https://iac.ethz.ch/group/ land-climate-dynamics/research/rietholzbach.html, last access: 16 February 2021).

At each site, all available meteorological data were included from the first point at which all five parameters were available (as early as 1981) until the end of 2019. Data gaps are generally short (hours to days) and were linearly interpolated in the CoupModel, except for precipitation, for which zero precipitation was assumed. Each complete time series was replicated prior to the first measurement by 2 randomly selected consecutive hydrological years (spin-up pe- riod). Both data gaps and spin-up periods, as well as the first 3 months after the spin-up period, were removed for the statistical analysis.

\subsection{Soil moisture data}

For assessing the CoupModel performance and for comparison of the simulation-based forecast model with a forecast model based on measurements (see Sect. 2.8), soil moisture measurements from 35 sites in Switzerland were included in the study (monitoring sites; Fig. 1a; Table 1). Soil moisture is measured with TDR or capacitance-based sensors at various depths along a soil profile, with the lowest sensors typically located at depths of $80-120 \mathrm{~cm}$. The data set includes sites from monitoring networks of various research institutions and authorities, and measurements were available at the earliest from 2008 until end of 2018. The data set was compiled and described in detail in a previous study (Wicki et al., 2020). 


\subsection{Landslide data}

Landslide records from the Swiss flood and landslide damage database (Swiss Federal Research Institute WSL; Hilker et al., 2009) were used to fit the landslide forecast model (see Sect. 2.8). The database includes landslide events which were identified from news articles in all of Switzerland since 1972. Records include coordinates, the date and time of the event (if known), and an event description.

For this study, events recorded from 1981 until end of 2019 were included. Following the approach of Wicki et al. (2020), deep-seated and human-induced landslides (e.g. pipe breaks and road embankment slips) were removed if explicitly mentioned in the event description. Furthermore, if no time of occurrence was specified, it was set to 12:00 Central European Time (CET), or, if the approximate timing was given in the event description, the timing was assumed (e.g. 09:00 CET for "in the morning"). In total, 2969 events were included in this study (Fig. 1a), 1041 of which contained a precise time information.

\subsection{Statistical landslide forecast model}

To assess the information content of the simulated soil moisture dynamics for regional landslide warning, a statistical framework was applied to the simulated soil moisture time series. This framework was developed in a previous study, where it was applied to in situ measured soil moisture in Switzerland (for a detailed description, see Wicki et al., 2020). It included first a normalization of soil moisture values by the minimum and the 99.5 percentile values to represent soil saturation, and the calculation of mean and standard deviation saturation at each soil profile for all model layers until $140 \mathrm{~cm}$ depth. At each profile, periods of continuous saturation increase (infiltration events) were then identified automatically based on the mean saturation time series. Each infiltration event was characterized by a set of event properties derived from both the mean and standard deviation time series (see Table 2). Finally, infiltration events were flagged as either landslide triggering or landslide nontriggering, provided that a landslide was observed or not observed, respectively, during the event period and within a specific distance from the modelling site (forecast distance).

A multiple logistic regression model was then fitted to the set of infiltration events where the binary outcome variable (i.e. the landslide triggering class of "yes" or "no") was modelled as a function of the independent infiltration event properties (explanatory variables). The logistic regression model yields a probability for each infiltration event to belong to the landslide triggering class (triggering probability). A fivefold cross-validation (CV) scheme was applied to assess the robustness of the model fit with equally sized folds and randomly selected infiltration events. A total of four folds were used to fit the model, and the remaining fold was used as the to make predictions. This approach is referred to as the vali- dation set approach, as opposed to the all data set approach, where the statistical model is fit to all the infiltration events.

\subsection{Skill of the landslide forecast}

To assess the forecast goodness of each specific statistical model fit, receiver operating characteristic analysis (ROC) was performed according to Fawcett (2006). First, a threshold was applied to reclassify the triggering probabilities of the infiltration events into the binary triggering classes landslide triggering or landslide nontriggering. A confusion matrix was constructed between observed and modelled triggering classes counting the number of true positives (TPs), true negatives (TNs), false positives (FPs) and false negatives (FNs). The true positive rate, $\mathrm{TPR}=\mathrm{TP} /(\mathrm{TP}+\mathrm{FN})$, and false positive rate, $\mathrm{FPR}=\mathrm{FP} /(\mathrm{FP}+\mathrm{TN})$, were computed accordingly. To assess the overall potential of a model fit for multiple thresholds, the threshold was varied 5000 times in equal steps between the minimum and maximum triggering probability, thus resulting in 5000 confusion matrices. The 5000 TPR and FPR pairs were then plotted in a $2 \mathrm{D}$ plot (ROC space), resulting in a cumulative curve (ROC curve) for which the area under the curve (AUC) was computed.

The forecast goodness of different model fits was assessed qualitatively by comparing the ROC curve and quantitatively by comparing the AUC value, which corresponds to the probability of listing a positive instance higher than a negative instance if sorted by the observed triggering class. A perfect classifier plots near the top left corner of the ROC space ( $\mathrm{AUC}=1.0$ ), whereas it is no better than random guessing if it plots along the $(0 / 0)$ to $(1 / 1)$ diagonal $(\mathrm{AUC}=0.5)$. To assess the distance dependence of the forecast models, each model set-up was fit using eight different forecast distances ranging in equal steps from 5 to $40 \mathrm{~km}$. We chose the ROC curve and AUC value as performance indicators because they assess the general forecast goodness of a statistical model in contrast to many other performance indicators that quantify the forecast goodness of specific threshold values (Piciullo et al., 2020).

\section{Results}

\subsection{General model performance}

The performance of the soil moisture model and the corresponding triggering probabilities according to the landslide forecast model are illustrated for a model set-up using a lower boundary condition, with groundwater and soil hydrological information from SoilGrids during a sample period from mid-April to mid-May 2015 (Fig. 3a). During this time period, a series of intense precipitation events led to widespread landslide activity in central Switzerland, with numerous landslides observed from 30 April until 4 May 2015 (black dots in Fig. 1b and colour-filled background in Fig. 3a, 
Table 2. List of event properties to describe infiltration events. To classify between triggering and nontriggering infiltration events, the nine event properties marked with " $x$ " are used. Time series of the mean of water saturation and standard deviation (SD) of saturation were used.

\begin{tabular}{|c|c|c|c|c|}
\hline Process domain & Event property description & Name & Profile mean & Profile SD \\
\hline \multirow[t]{3}{*}{ Antecedent conditions } & Saturation at the onset of infiltration event & Antecedent sat. & $\mathrm{x}$ & \multirow[t]{3}{*}{$\mathrm{x}$} \\
\hline & A 2-week preceding maximum saturation & 2 week-prec. max sat. & $\mathrm{x}$ & \\
\hline & A 2-week preceding mean saturation & 2 week-prec. mean sat. & $\mathrm{x}$ & \\
\hline \multirow[t]{4}{*}{ Event dynamics } & Saturation change during an infiltration event & Sat. change & $\mathrm{x}$ & \multirow[t]{4}{*}{$\mathrm{x}$} \\
\hline & Infiltration rate & Infiltration rate & $\mathrm{x}$ & \\
\hline & Maximum $3 \mathrm{~h}$ infiltration rate & Max inf. rate & $\mathrm{x}$ & \\
\hline & Event duration & Duration & $\mathrm{x}$ & \\
\hline
\end{tabular}

b). Profile saturation for a subset of 11 sites in the region of interest (coloured points in Fig. 1b) remained low and inhomogeneous prior to the landslide period. It increased to near-saturated conditions and remained very wet for a couple of days, which coincides with the period of landslide activity. This development is confirmed by the landslide forecast model (fitted here for the $15 \mathrm{~km}$ forecast distance), which shows a low triggering probability at the beginning of the period (red horizontal lines; note that landslide probability is only computed for periods of saturation increase). Triggering probability increased significantly across all sites during the period of landslide activity and descended again after that. While the relative triggering probability increases are considerable, absolute probability values remain low even during landslide-triggering events. This is the case for all infiltration events and can be attributed to an unbalanced data set (i.e. the ratio of landslide triggering to landslide nontriggering events is very low; ratio not shown). It is commonly reported for logistic regression models with these types of data sets (King and Zeng, 2001).

These patterns can be compared to in situ soil moisture measurements at the same sites and the corresponding landslide forecasts of a forecast model fitted to the soil moisture measurements (Fig. 3b). Temporal evolution of the profile saturation shows similar regional-scale patterns with variably saturated conditions during the first half of the sample period followed by an increased saturation during the period of landslide activity. Furthermore, the measurement-based landslide forecast model shows a similar triggering probability development to the simulation-based model, with significantly higher triggering probabilities for all sites during the days of observed landslide events compared to the periods prior to and after that. Yet, distinct differences are apparent. The temporal evolution of simulated profile saturation appears to be more homogeneous between different sites; the desaturation immediately after an infiltration event is slower, and it reaches drier conditions after sustained periods of no infiltration. Triggering probabilities are generally lower for the measurement-based landslide forecast model.

\subsection{Performance assessment of the soil hydrological model}

The agreement between simulated and observed soil wetness was analysed for the 14 reference sites by the mean error (ME) and coefficient of determination $\left(R^{2}\right)$ statistics computed for the hourly soil moisture values. The skill of the model set-up was generally solid but strongly varied from site to site and with the depth of the sensors (Fig. 4a). Best agreement was found for the top-most sensors (median $\mathrm{ME}=0.00 \mathrm{~m}^{3} \mathrm{~m}^{-3}$; median $R^{2}=0.55-0.60$ ). At depths of 30 and $50 \mathrm{~cm}, \mathrm{ME}$ values were similar, but $R^{2}$ values were lowest across all depths (median $R^{2}=0.40-0.45$ ). $R^{2}$ statistics were better at $80 \mathrm{~cm}$ depth (median $R^{2}=0.50-0.55$ ); however, mean error was greater than at all other depths (median $\mathrm{ME}=0.02-0.05 \mathrm{~m}^{3} \mathrm{~m}^{-3}$ ), indicating too dry conditions at the lower boundary, probably due to overestimation of deep percolation. This skill is comparable to or slightly lower than reported skills for other soil moisture models used in landslide early warning (e.g. Brocca et al., 2008; Thomas et al., 2018) or for CoupModel set-ups with different purposes (e.g. Conrad and Fohrer, 2009; He et al., 2016). However, it has to be noted that these models are mostly validated for one or two sites only and were partially calibrated site specifically.

Not much difference in model skill was found between using a lower boundary condition without groundwater (Fig. 4a) and with groundwater (Fig. 4b). When a lower boundary with groundwater was defined, ME statistics remained very similar (median $\mathrm{ME}=0.00-0.05 \mathrm{~m}^{3} \mathrm{~m}^{-3}$ ), and $R^{2}$ statistics slightly improved at the lowest depths (median $R^{2}=0.45$ at $50 \mathrm{~cm}$; median $R^{2}=0.60$ at $80 \mathrm{~cm}$ ). Best model fit of the groundwater-based model set-up was found for a parameterization indicative of a well-drained site.

Another important part in the parameterization is the sitespecific definition of the soil hydrological properties. Since texture and bulk density information from soil samples were available for the monitoring sites only, they were derived from a gridded product (SoilGrids) in order to be able to apply the CoupModel with the same general set-up at all sites. Comparison of a soil-samples-based model set-up (Fig. 4a, b) 


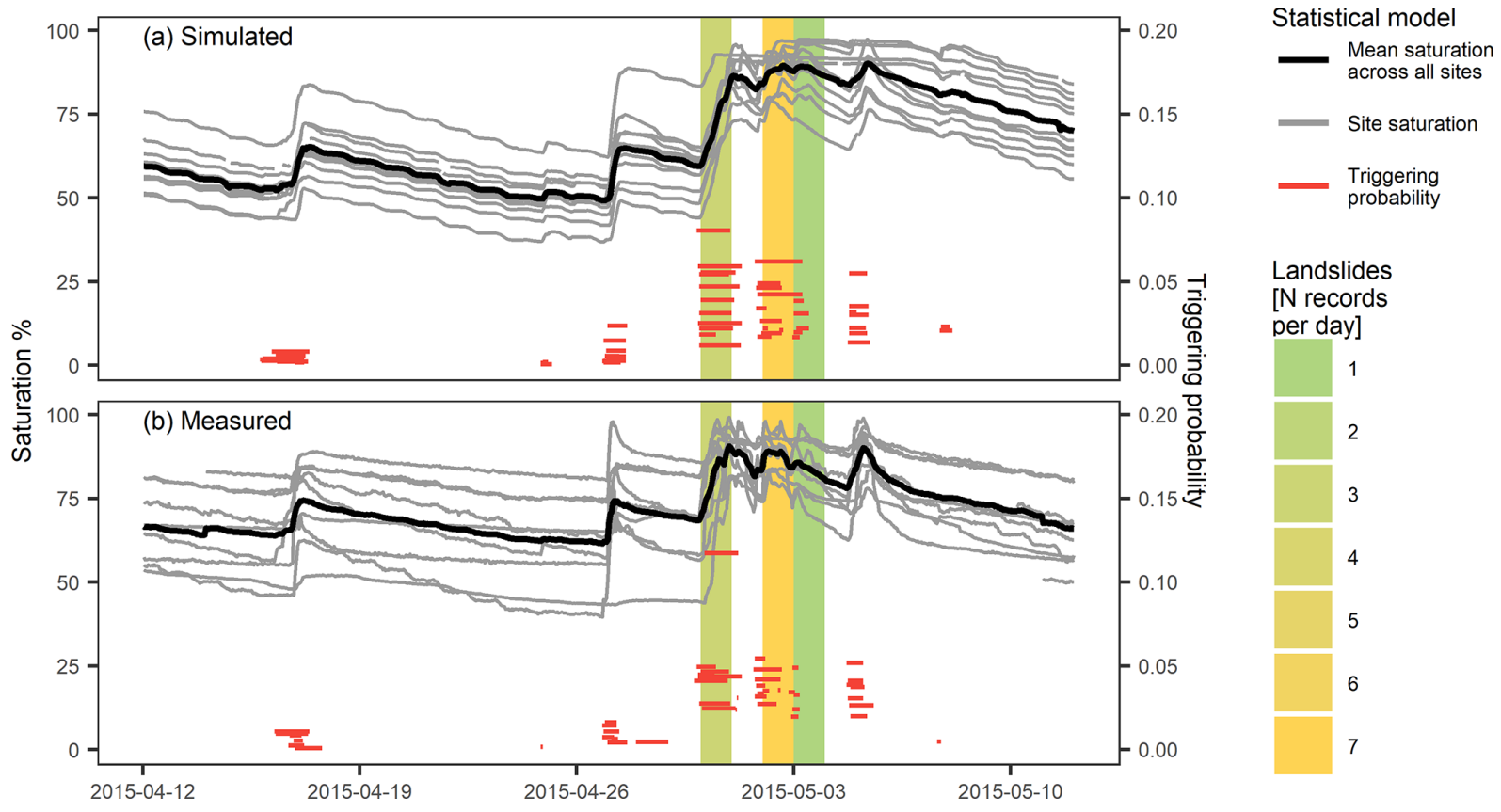

Figure 3. Profile saturation (grey lines) of a selection of 11 sites in central Switzerland (as depicted in Fig. 1b), with the mean profile saturation across all selected sites (black line), during a period of increased landslide activity in April and May 2015 for (a) simulated (lower boundary with groundwater and soil hydrological properties from SoilGrids) and (b) measured soil moisture. The colour-filled background denotes days with observed landslide events within $15 \mathrm{~km}$ of any of the sites, with the colour indicating the number of landslide records. The red lines show the associated landslide triggering probability from the statistical model (based on the nine infiltration event properties listed in Table 2) at each site, which was computed for periods of saturation increase only.

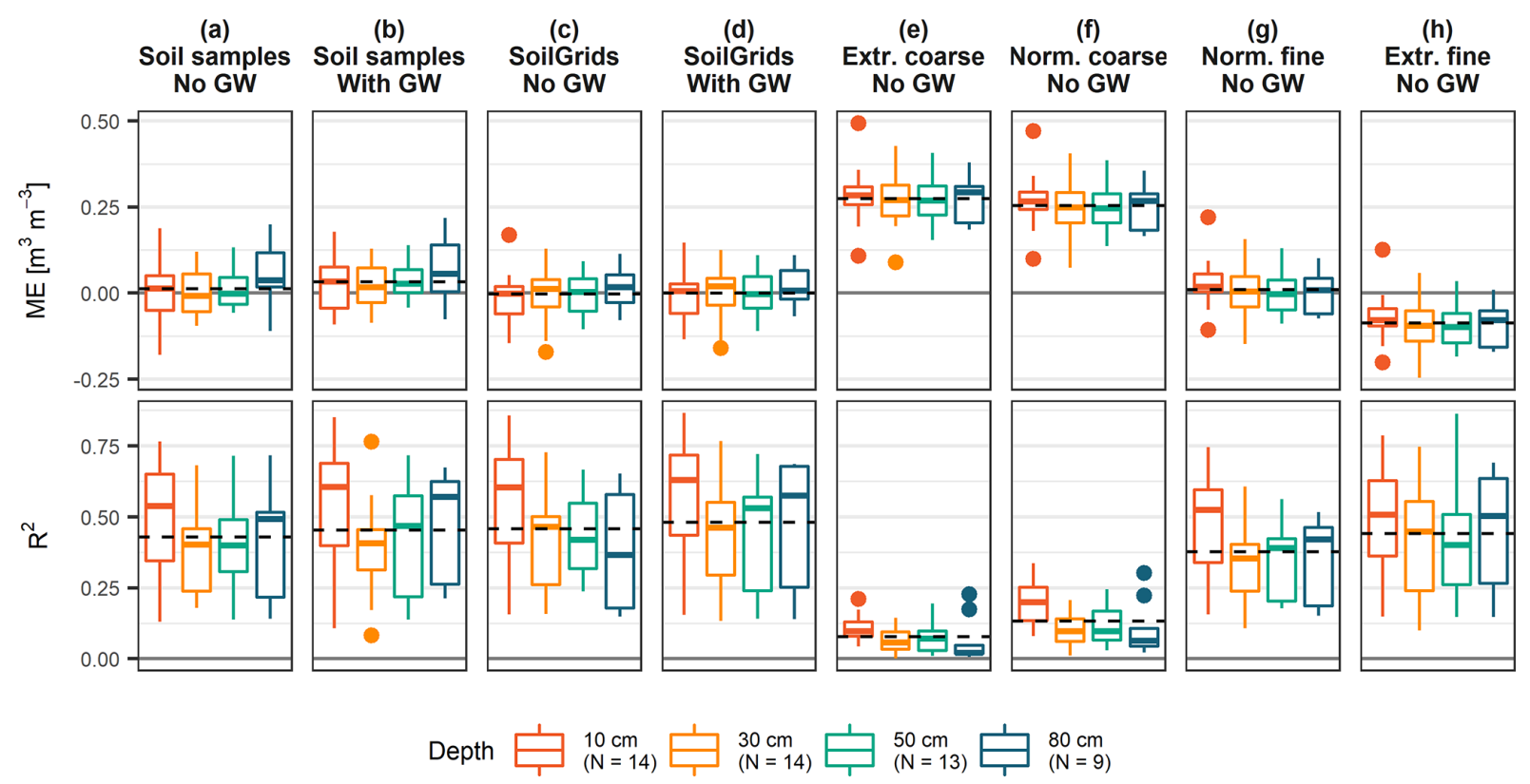

Figure 4. Goodness of fit of simulated versus measured soil moisture variation at the 14 reference sites, with the mean error (ME; top panels) and coefficient of determination $\left(R^{2}\right.$; bottom panels) indicated by sensor depths (different colours) for various CoupModel parameterizations (a-h). Lower boundary conditions with and without groundwater $(\mathrm{GW})$ are distinguished. 
with a model set-up based on SoilGrids information (Fig. 4c, d) revealed very similar model skill, with a slightly decreased mean error (median $\mathrm{ME}=0.00 \mathrm{~m}^{3} \mathrm{~m}^{-3}$ at all depths) and slightly larger range of $R^{2}$ values for the SoilGrids-derived model set-up. This indicates that SoilGrids adequately represents the regional variation in soil hydrological variability and can be used to extend the model to all other sites. Furthermore, the effect of having no regional variation in soil hydrological properties was tested by deriving them from the normal, fine-grained uniform texture profile (Fig. 4g). Mean error statistics remained in a similar range (median $\mathrm{ME}=0 \mathrm{~m}^{3} \mathrm{~m}^{-3}$ at all depths); however, $R^{2}$ values were significantly lower at all depths (median $R^{2}=0.30-0.55$ ). This demonstrates the value of including regionally varying soil hydrological properties.

Finally, large sensitivity of the model skill was found for variation in the saturated hydraulic conductivity, which was tested by deriving the soil hydrological properties from the other, more extreme uniform texture profiles. Above-average $K_{\mathrm{S}}$ values were defined for profiles representing extreme coarse-grained and normal, coarse-grained soils (Fig. 4e, f), and $K_{\mathrm{s}}$ values were below average for the extreme finegrained uniform texture profile (Fig. 4h). Model skill showed a very poor model fit for the coarse-grained profiles (median $R^{2}=0.05-0.20$ ) and very high mean error values indicative for too dry conditions (median $\mathrm{ME}=0.25 \mathrm{~m}^{3} \mathrm{~m}^{-3}$ at all depths). Model fit was better for the extreme finegrained profile (median $R^{2}=0.40-0.50$ ), but ME statistics showed too wet conditions (median $\mathrm{ME}=-0.10 \mathrm{~m}^{3} \mathrm{~m}^{-3}$ at all depths). This indicates that the SoilGrids and soil samples derived saturated hydraulic conductivity values are of an adequate order of magnitude.

One important result of our soil moisture model assessment was the fact that the deviation between model and measurement, i.e. the residuals, were not varying randomly, but had a seasonal trend (Fig. 5a, b; residuals were computed as mean daily values across all 14 sites). With a CoupModel set-up using SoilGrids information and a bottom boundary condition with groundwater, winter months showed positive anomalies (i.e. modelled soil moisture was drier than observed), whereas negative anomalies (i.e. wetter than observed) were apparent during summer months. Both effects were more pronounced in near-surface layers. Furthermore, near-surface layers showed wetter than observed anomalies, after the exceptionally dry summer in 2015, and negative trends not seen in the modelling. We explain the underestimation of the seasonal variation with an underestimation of evapotranspiration in summer (too wet conditions in summer when evapotranspiration is high) and a generally faster drainage than observed (too dry conditions in winter when evapotranspiration is low). The overall negative trend in the anomalies (dashed lines in Fig. 5c) may be explained by an underrepresentation of evapotranspiration in exceptionally dry summers. However, it might as well be related to data quality issues and reduced homogeneity of the long-
Table 3. Percentage of country (area of Switzerland) and number of landslides (percentage of all landslides recorded from 1981 to 2019) covered by the soil moisture simulations and measurements as a function of the forecast distance used.

\begin{tabular}{lrr|rr}
\hline & \multicolumn{2}{c|}{ All sites (133 sites) } & \multicolumn{2}{c}{ Monitoring sites (35 sites) } \\
\cline { 2 - 5 } $\begin{array}{l}\text { Forecast } \\
\text { distance }\end{array}$ & $\begin{array}{r}\text { Percent of } \\
\text { total area }\end{array}$ & $\begin{array}{r}\text { Percent of } \\
\text { all landslides }\end{array}$ & $\begin{array}{r}\text { Percent of } \\
\text { total area }\end{array}$ & $\begin{array}{r}\text { Percent of } \\
\text { all landslides }\end{array}$ \\
\hline $5 \mathrm{~km}$ & 22.6 & 26.8 & 6.4 & 7.1 \\
$10 \mathrm{~km}$ & 65.6 & 73.7 & 22.1 & 26.0 \\
$15 \mathrm{~km}$ & 91.4 & 95.4 & 41.5 & 49.6 \\
$20 \mathrm{~km}$ & 98.6 & 99.2 & 58.0 & 65.8 \\
$25 \mathrm{~km}$ & 99.7 & 99.8 & 70.3 & 76.4 \\
$30 \mathrm{~km}$ & 100.0 & 100.0 & 79.3 & 83.1 \\
$35 \mathrm{~km}$ & 100.0 & 100.0 & 87.0 & 88.6 \\
$40 \mathrm{~km}$ & 100.0 & 100.0 & 92.6 & 93.7 \\
\hline
\end{tabular}

term soil moisture measurements which have been partially running for up to 10 years (e.g. due to compaction of the soil or enhanced root development around the sensors towards the end of the monitoring period). Furthermore, the different sites each have different lengths of records which may impact the homogeneity of the aggregated signal.

\subsection{Performance of the statistical landslide forecast model}

\subsubsection{Simulated versus observed soil moisture; 35 monitoring sites}

ROC curves and AUC values for a CoupModel set-up with groundwater and, using soil hydrological properties derived from soil samples, are shown in Fig. 6a. For comparison with a measurement-based statistical model fit, the data set contains the 35 monitoring sites only, and modelling periods were limited to the same periods for which soil moisture measurements were available (2008-2018). ROC curves of all forecast distances clearly deviated from the $(0 / 0)$ to $(1 / 1)$ line, and most AUC values were larger than 0.8, indicating that all forecast distances bore some information content on the regional landslide activity. Forecast goodness was strongly distance dependent, with short forecast distances having a better forecast goodness (AUC $=0.86$ at $5 \mathrm{~km}$; AUC $=0.79$ at $40 \mathrm{~km}$; all data set approach). This is in good agreement to the results of Wicki et al. (2020) for measured soil moisture. The robustness of the statistical model fit was assessed by comparison with the AUC values and ROC curves of the validation set approach (Fig. 6e). Values were very similar for most forecast distances, indicating a robust model fit; however, robustness was slightly lower at short forecast distances, probably due to the low number of landslide records ( $7 \%$ of all landslides were within the $5 \mathrm{~km}$ radius of the 35 sites; see Table 3 ).

Compared to a statistical model derived from measured soil moisture (Fig. 6d, h), the number of infiltration 


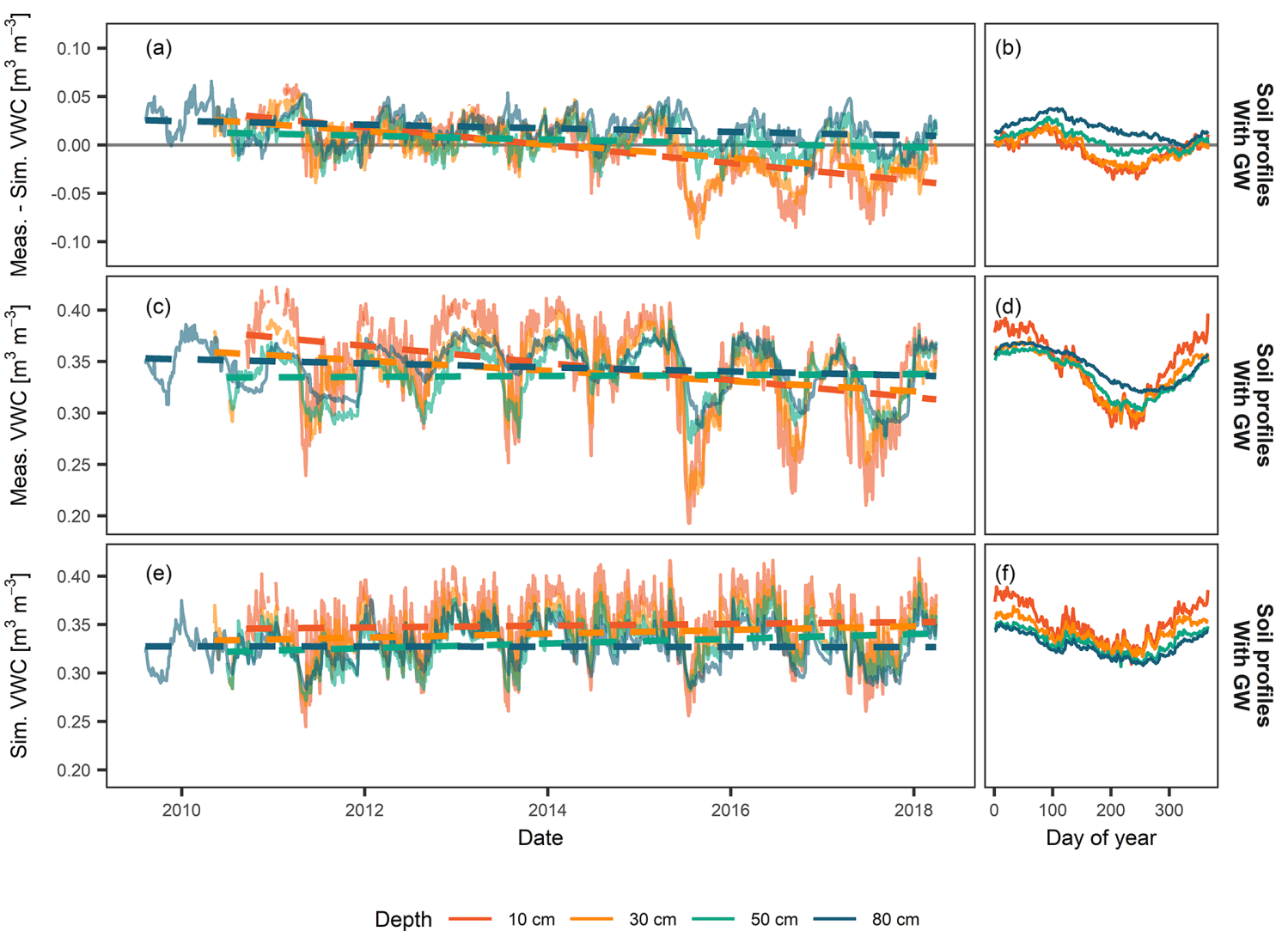

Figure 5. Temporal evolution of, and seasonal variation in, mean daily residual volumetric water content (VWC) (a, b), i.e. the deviation between simulated and observed soil water content, and mean daily measured (c, d) and simulated VWC (e, f). Means are calculated across all 14 reference sites by sensor depths (different colours) for a CoupModel set-up using soil hydrological properties derived from SoilGrids and a lower boundary condition with groundwater.

events was similar, yet the overall forecast goodness of the measurement-based forecast model was lower at all forecast distances $(\mathrm{AUC}=0.83$ at $5 \mathrm{~km} ; \mathrm{AUC}=0.72$ at $40 \mathrm{~km}$; all data set approach). This is remarkable as the simulated soil moisture was shown to contain specific uncertainty, particularly related to the long-term water storage in the soil. We explain the better forecast goodness of the simulation-based landslide forecast model by a more homogeneous representation of infiltration characteristics in space (less influence of local conditions, such as groundwater influence or preferential infiltration) and in time (no drift or trend as might be observed for some erroneous or badly coupled soil moisture sensors), as well as a more homogeneous site representation (number of sensors and depth levels included in the analysis).

\subsubsection{Simulated soil moisture using in situ soil physical properties versus using SoilGrids}

A similar forecast goodness resulted for a simulation with SoilGrids-derived soil hydrological properties compared to a simulation with soil hydrological properties derived from soil samples (Fig. 6b, f). AUC values and number of infiltration events were in the same range $(\mathrm{AUC}=0.87$ at $5 \mathrm{~km}$;
AUC $=0.78$ at $40 \mathrm{~km}$; all data set approach), and ROC curves followed a similar shape with more robust model fits at large forecast distances. This finding is in line with the similar goodness of fit as shown in the previous section and demonstrates the validity of using soil hydrological properties derived from SoilGrids. It permits the extension of the approach to all 133 sites, most of which had no in situ soil sample information available.

\subsubsection{Increase in number of soil moisture sites}

Extending the analysis to all 133 sites and to the entire input data time period (1981-2019) resulted in a considerably higher number of infiltration events $(N=142311)$ and, thus, much smoother ROC curves (Fig. 6c, g). Furthermore, the model fits became very robust even at short forecast distances (i.e. same AUC values for the all data set and validation set approaches). AUC values were slightly lower than when the 35 monitoring sites were used, but were in the same range $(\mathrm{AUC}=0.87$ at $5 \mathrm{~km} ; \mathrm{AUC}=0.76$ at $40 \mathrm{~km})$, and $\mathrm{ROC}$ curves bulged slightly less to the top, indicating a worse performance for optimistic thresholds. 

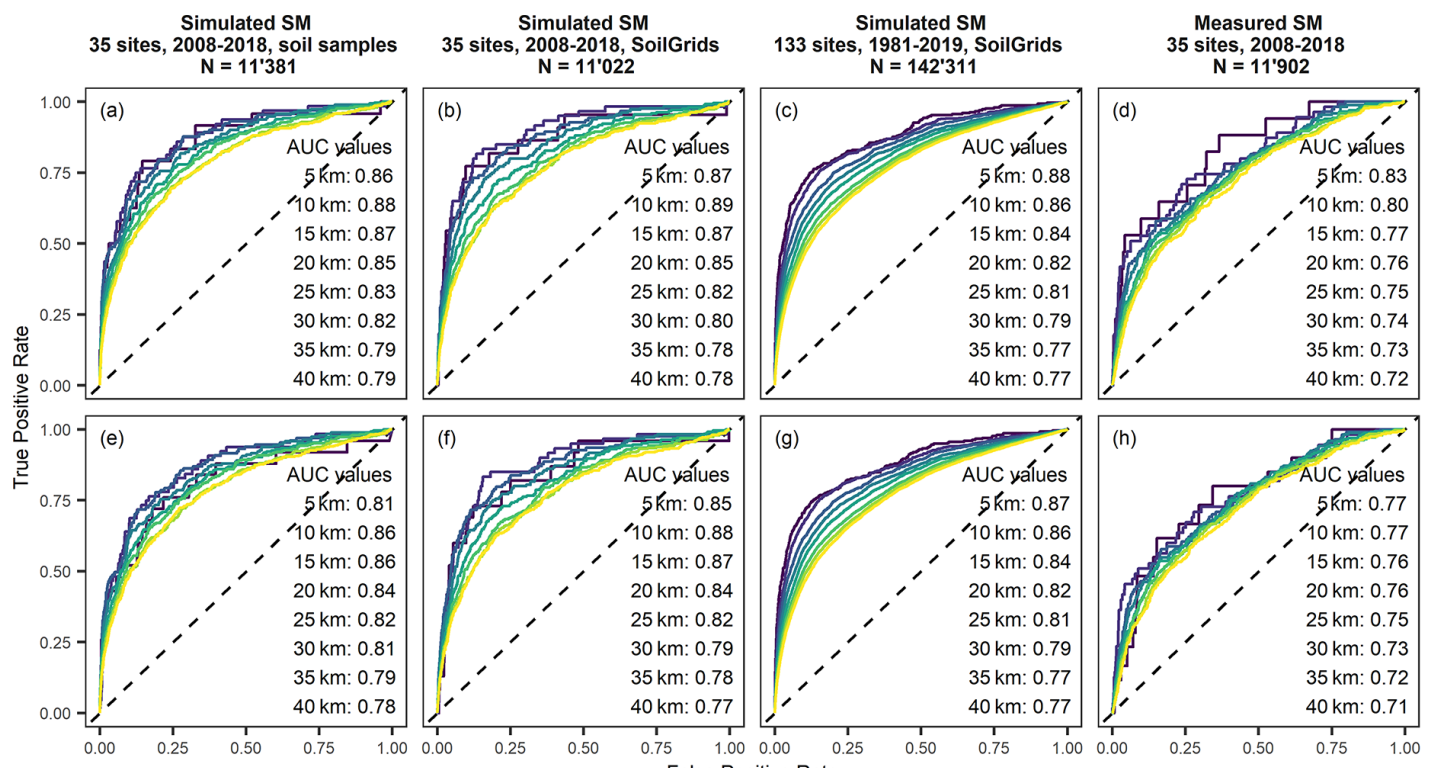

Forecast
Distance

Distance
$[\mathrm{km}]$

$-5$
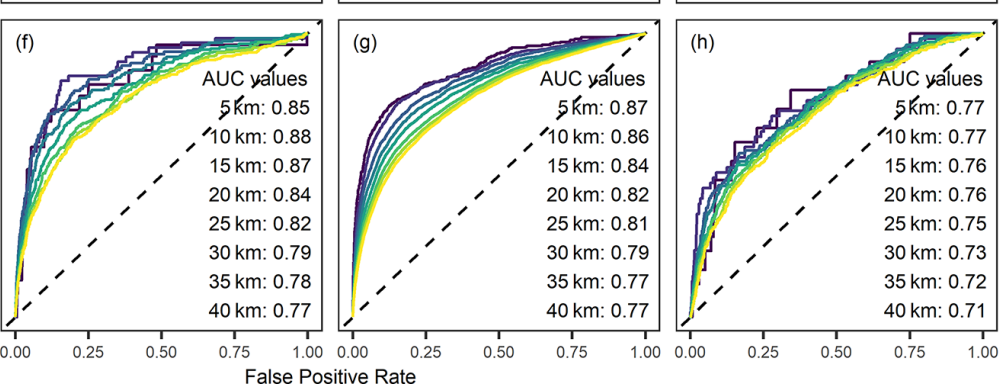

Figure 6. ROC plots and AUC values of landslide forecast model fits based on simulated soil moisture (SM) at the 35 monitoring sites, including soil hydrological properties from soil samples $(\mathbf{a}, \mathbf{e})$ and SoilGrids $(\mathbf{b}, \mathbf{f})$ at all 133 sites and including soil hydrological properties from SoilGrids $(\mathbf{c}, \mathbf{g})$, and based on measured soil moisture at the 35 monitoring sites $(\mathbf{d}, \mathbf{h})$. All CoupModel set-ups include a lower boundary condition with groundwater. Panels (a)-(d) show landslide forecast model fits using all the data sets, whereas panels (e)-(h) show model fits based on the fivefold cross-validation scheme.

Increasing the number of sites also increased the area and number of landslides covered, as illustrated with Table 3. When all 133 sites were used, almost the whole country and all landslides were covered by using a $15 \mathrm{~km}$ forecast distance. When the 35 monitoring sites were used only (as was the case for the measurement-based forecast model), the same coverage is only possible when a $40 \mathrm{~km}$ forecast distance is used. This is due to the lower number of sites and because the available sites are distributed inhomogeneously, including large gaps in alpine areas and in the eastern part of the country (Fig. 1a).

\subsubsection{Sensitivity of the landslide forecast model to the definition of the lower boundary condition and soil properties}

The sensitivity of the landslide forecast model to changes in the lower boundary condition was assessed by testing different lower boundary parameterizations for CoupModel set-up using all 133 sites (Fig. 7; grey boxes highlight the model parameterization that was chosen for the goodness of fit analysis). Low sensitivity of the landslide forecast goodness was found for variations in the lower boundary conditions without groundwater (Fig. 7a), which was defined by the maximum pressure head of the lowest layer above which outflow occurs as gravitational outflow. In contrast, when the lower boundary was defined with a seepage function, the landslide forecast goodness was very variable. Best results were obtained for a fairly steep gradient to the drain, i.e. a larger depth to drain (Fig. 7b) or a shorter distance to drain (Fig. 7c). This indicates a better landslide forecast goodness for well-drained sites. As shown previously, the landslide forecast goodness was similar for both a CoupModel parameterization with or without groundwater, which is in line with the very similar goodness of fit values for the two parameterizations.

Low sensitivity of the landslide forecast model was found when using soil hydrological properties derived from uniform texture profiles (Fig. 8), resulting even in a slight forecast goodness increase for the extreme and normal, coarsegrained, uniform texture profiles. This is surprising since, by using uniform texture profiles, the regional variation in soil hydrological properties is disregarded, and $K_{\mathrm{S}}$ values partially deviate substantially from what can be expected in reality, both of which were reflected with a substantially worse agreement with measured soil moisture in a previous section. The reasons behind this are studied in more detailed in Sect. 4.

\subsection{Most important explanatory variables for landslide forecast model}

In the previous section, the landslide prediction models were fitted, including all explanatory variables (also referred to as event properties) as listed in Table 2. In order to analyse the contribution of individual explanatory variables to the overall forecast goodness, the landslide prediction model was fitted to individual explanatory variables only, as illus- 


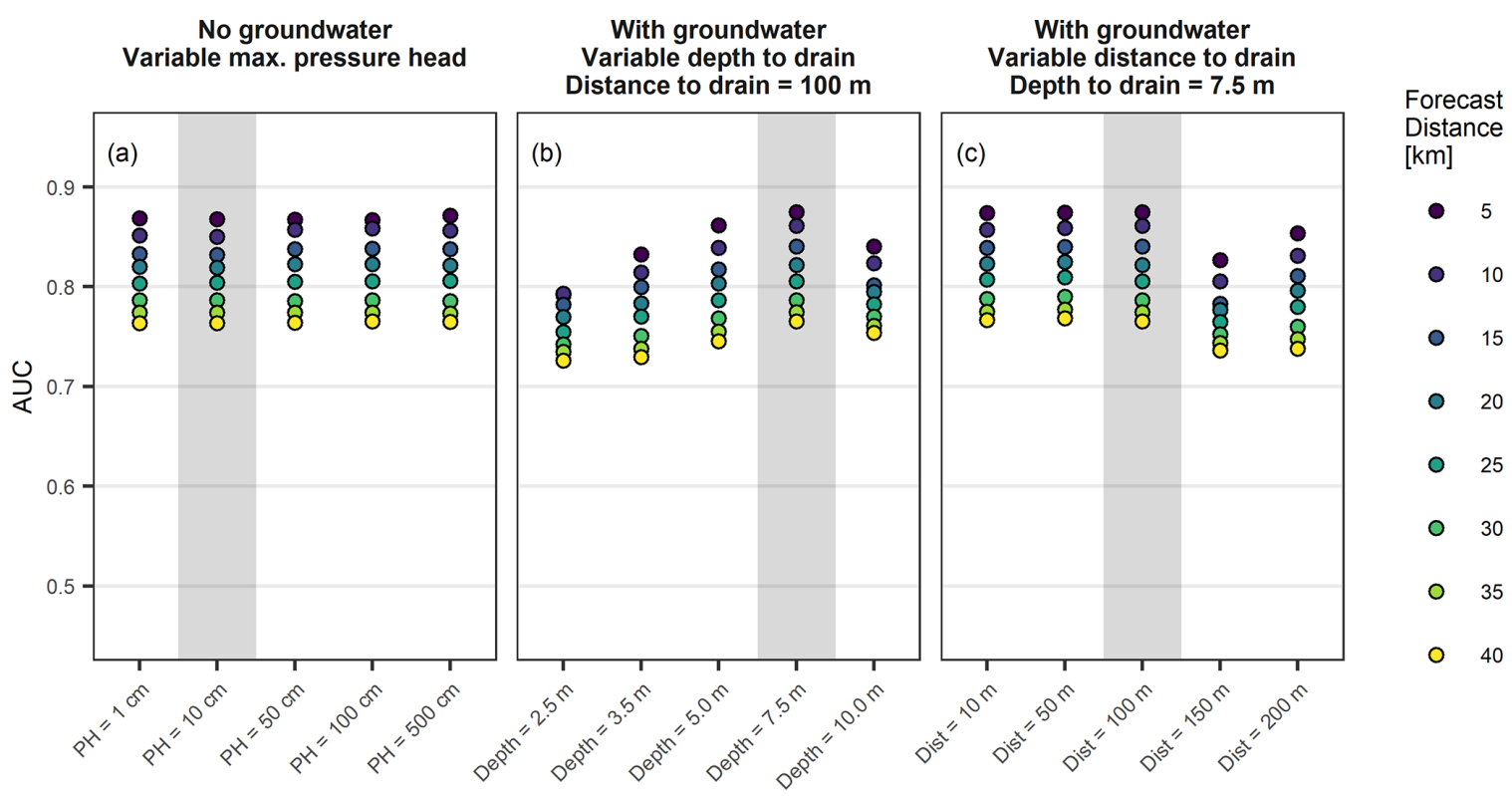

Figure 7. AUC values of landslide forecast model fits with different parameterizations of the lower boundary condition by varying (a) the maximum pressure head of the lowest layer above which exfiltration occurs, (b) depth to the drain and (c) the distance to the drain. Grey shaded model runs correspond to the CoupModel parameterization used in all other analyses.

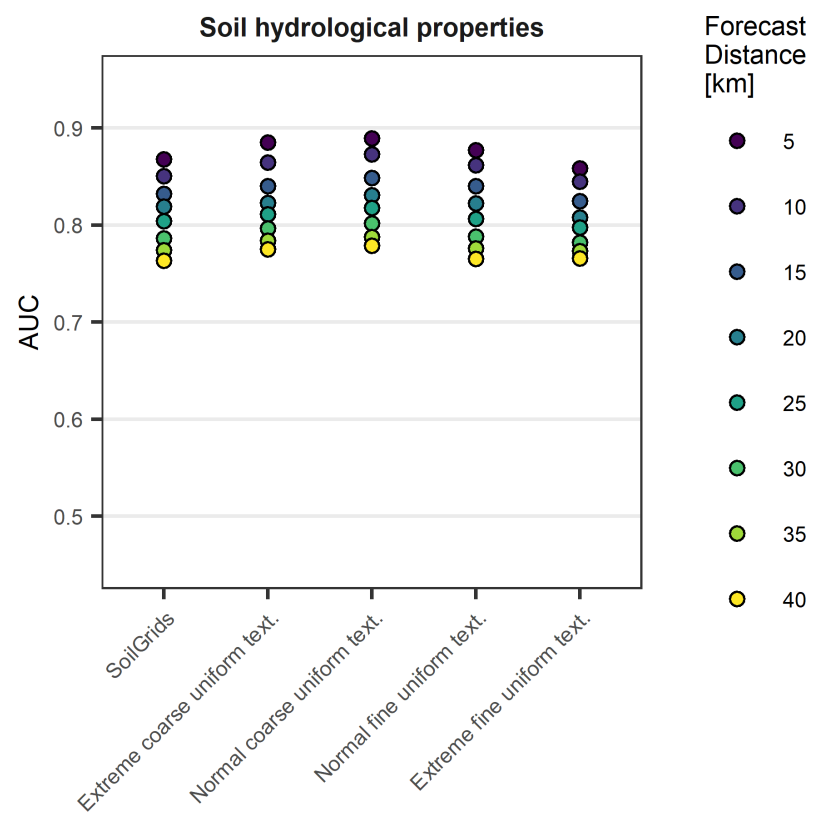

Figure 8. AUC values of landslide forecast model fits based on CoupModel set-ups with varying soil hydrological properties (derived from SoilGrids and uniform texture profiles) and a lower boundary condition with groundwater.

trated in Fig. 9 (first column), where AUC values are plotted for different statistical model fits. Explanatory variables can be grouped into variables describing the antecedent wetness conditions (shaded in red) and into variables describing the infiltration event dynamics (shaded in orange). For reference, a model fit including two explanatory variables only (antecedent saturation and saturation change; second column) and a model fit including all explanatory variables (third column) are plotted too. As expected, the forecast goodness of individual explanatory variables was significantly lower than when all explanatory variables were included. Furthermore, model fits using the two explanatory variables antecedent the saturation and saturation change had almost the same forecast goodness as if all event properties were used.

When looking at individual explanatory variables in detail, distinct differences become apparent between statistical model fits based on simulated and measured soil moisture. For the simulation-based landslide forecast models, the increase in the forecast goodness was mostly driven by explanatory variables that describe the triggering event dynamics (e.g. saturation change during the infiltration event, maximum $3 \mathrm{~h}$ infiltration rate, infiltration rate and standard deviation change; Fig. 9a, d, g). Inversely, for a measurementbased landslide forecast model, explanatory variables related to the antecedent wetness conditions were more important (e.g. antecedent saturation and the 2 weeks preceding the maximum saturation; Fig. 9k).

The worse performance of explanatory variables related to the antecedent wetness conditions for the simulation-based forecast models can be related to the reduced ability of the CoupModel set-up to reflect long-term seasonal water storage, as described previously (Fig. 5). The better forecast goodness of explanatory variables related to the triggering event dynamics of the simulation-based landslide forecast model can be explained by a more homogeneous site set-up, 
no impact by very site-specific conditions (e.g. preferential flow, interaction with a local groundwater table and interaction with the vegetation) and by the elimination of measurement errors (e.g. sensor drift, sensor uncertainties and bad sensor contact to surroundings).

The better performance of explanatory variables related to event dynamics compared to those related to antecedent conditions was even more accentuated in the case of the extreme coarse-grained, uniform texture profile with a better forecast goodness of most of the event-dynamics-related explanatory variables (Fig. 9g). Conversely, the antecedent saturation explanatory variable even showed a slight forecast goodness decrease.

\section{Discussion}

\subsection{Limitations of the soil moisture model}

The soil moisture model incorporates errors and uncertainties connected to the parameterization and the quality of the input data, limiting the availability to reproduce soil moisture variation as observed with soil moisture sensors. A large component of uncertainty originates from the definition of the soil hydrological properties, which, in previous studies, were shown to have a great impact on simulated soil moisture and landslide forecasts (e.g. Thomas et al., 2018). Here, uncertainty is added from both the definition of the site-specific texture and bulk density values, as well as from the estimation of the soil physical properties with a pedotransfer function. No substantial differences in the goodness of fit of simulated versus observed soil moisture were found between using soil hydrological properties derived from soil samples and those taken from SoilGrids. Yet, a decrease in the correlation coefficient was found when using the same normal, fine-grained uniform texture profile for all sites. From that, we can conclude that the soil hydrological property differences between using soil samples and SoilGrids are smaller than the missing regionalization inferred by using a uniform texture profile only. This underlines the importance of using regionally varying soil physical information for simulating soil moisture, which is often omitted due to a lack of field data or because too many parameters may lead to overfitting problems (e.g. Posner and Georgakakos, 2015; Zhao et al., 2019b).

Larger uncertainty is probably introduced by the use of a pedotransfer function to infer the soil hydrological properties from soil physical information. This point cannot be validated directly since field data on site-specific soil hydrological properties is missing; however, the large ME spread across the 14 reference sites points towards partially incorrect residual $\theta_{\mathrm{r}}$ and saturated water content $\theta_{\mathrm{S}}$ values. Furthermore, many studies highlight that pedotransfer functions incorporate a bias towards loamy agricultural soils and lack a representation of soil structure, such as the presence of macropores or concretizations (e.g. Or, 2020; Zhang and Schaap, 2019). This may lead to an underestimation of $K_{\mathrm{S}}$ values which, in return, impacts surface runoff generation, water infiltration and discharge (Fatichi et al., 2020).

A second major source of uncertainty originates from the definition of homogeneous upper and lower boundary conditions. In general, seasonal soil moisture variation was underestimated, a problem also reported in other modelling studies (Okkonen et al., 2017; Orland et al., 2020; Zhuo et al., 2019a) and which may be partially attributed to the definition of the vegetation and soil resistances and the potential evapotranspiration calculation. Calibration is difficult due to missing evapotranspiration measurements. We compared our evapotranspiration estimates with a countrywide evapotranspiration estimation function for grassland locations depending on elevation (Hydrological Atlas of Switzerland - HADES; Menzel et al., 1999) and with estimations from lysimeter measurements at the Rietholzbach site (RHB; Hirschi et al., 2017). It was shown that evapotranspiration estimates slightly underestimated the HADES values; however, they followed the same elevation dependence (Fig. 10a). When comparing with field lysimeter data, evapotranspiration estimates were lower too (Fig. 10b) but followed the general seasonal variation and showed similar interannual variation except for the year of 2008 (Fig. 10c). This may explain the underestimated drying out of the model compared with the observations as shown previously, which could be improved by a more elaborate or site-specific vegetation parameterization. Nevertheless, the evapotranspiration data presented here are only weakly representative and serve as a rough point of reference as they are based on simulations and show regional values (in case of HADES), and lysimeter measurements were available for one site only (RHB).

At the lower boundary of the soil profile, the definition of well-drained conditions showed the best results. However, soil hydrological conditions might differ substantially for individual sites if shallow groundwater tables are present (Marino et al., 2020) or if soil depths vary between the sites (Anagnostopoulos et al., 2015); hence, a site-specific parameterization might improve the goodness of fit with observed soil moisture variation. While no seepage data on regional scales were available for calibration or validation, a sitespecific definition of lower boundary conditions could be achieved by consideration of nearby groundwater-level measurements or regional groundwater distribution maps when defining the depth and distance to drain for a lower boundary with groundwater.

Finally, when comparing the goodness of fit with observed soil moisture measurements, it has to be noted that the soil moisture measurements bear uncertainties too and might be erroneous or contain a signal shift or trend due to bad contact with the surrounding material, sensor deterioration or structural changes in soil. Thus, a thorough quality assessment is needed when using soil moisture data for calibration or validation. Further to that, measurement uncertainties of the 

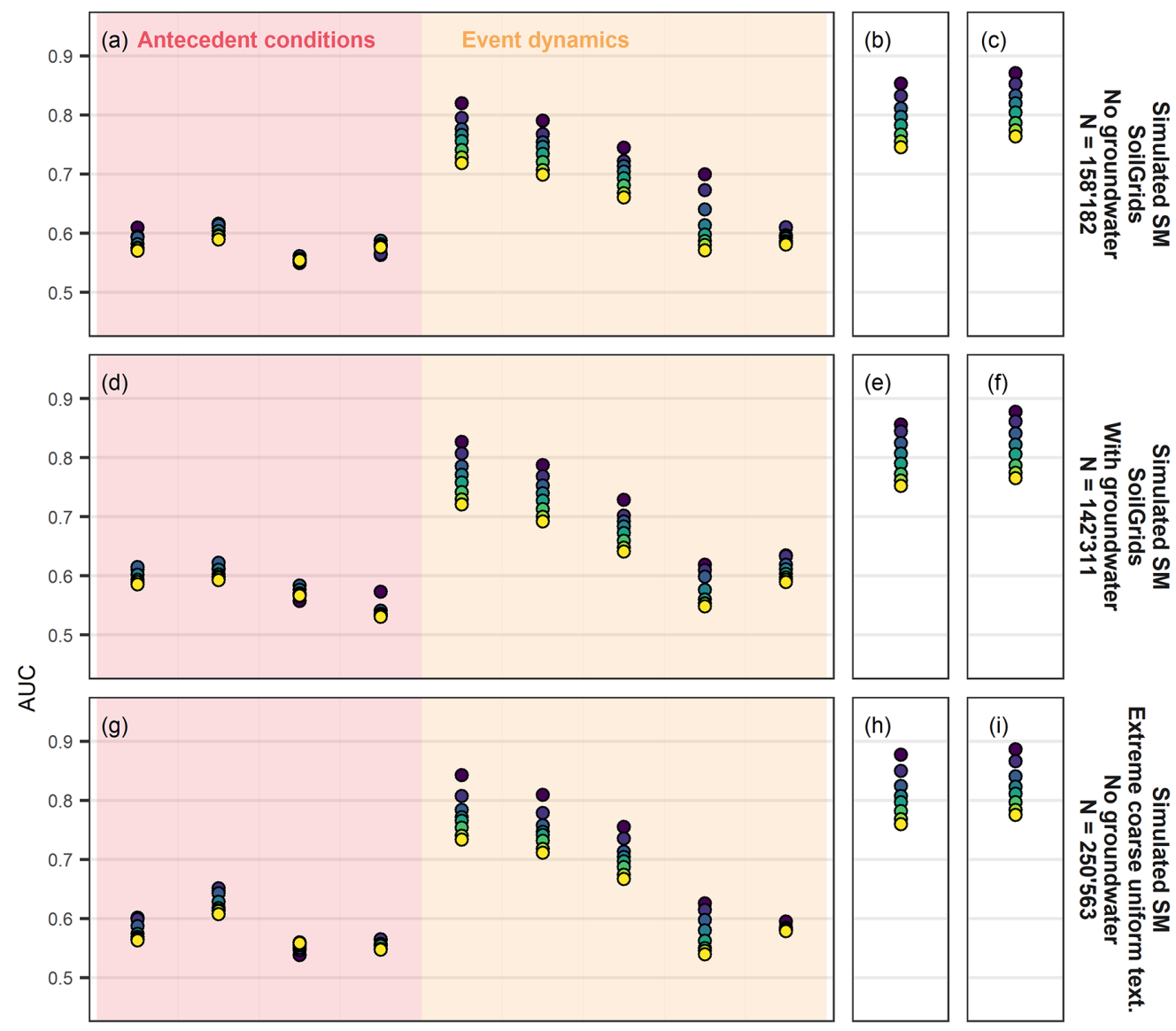

Forecast

Distance

[km]
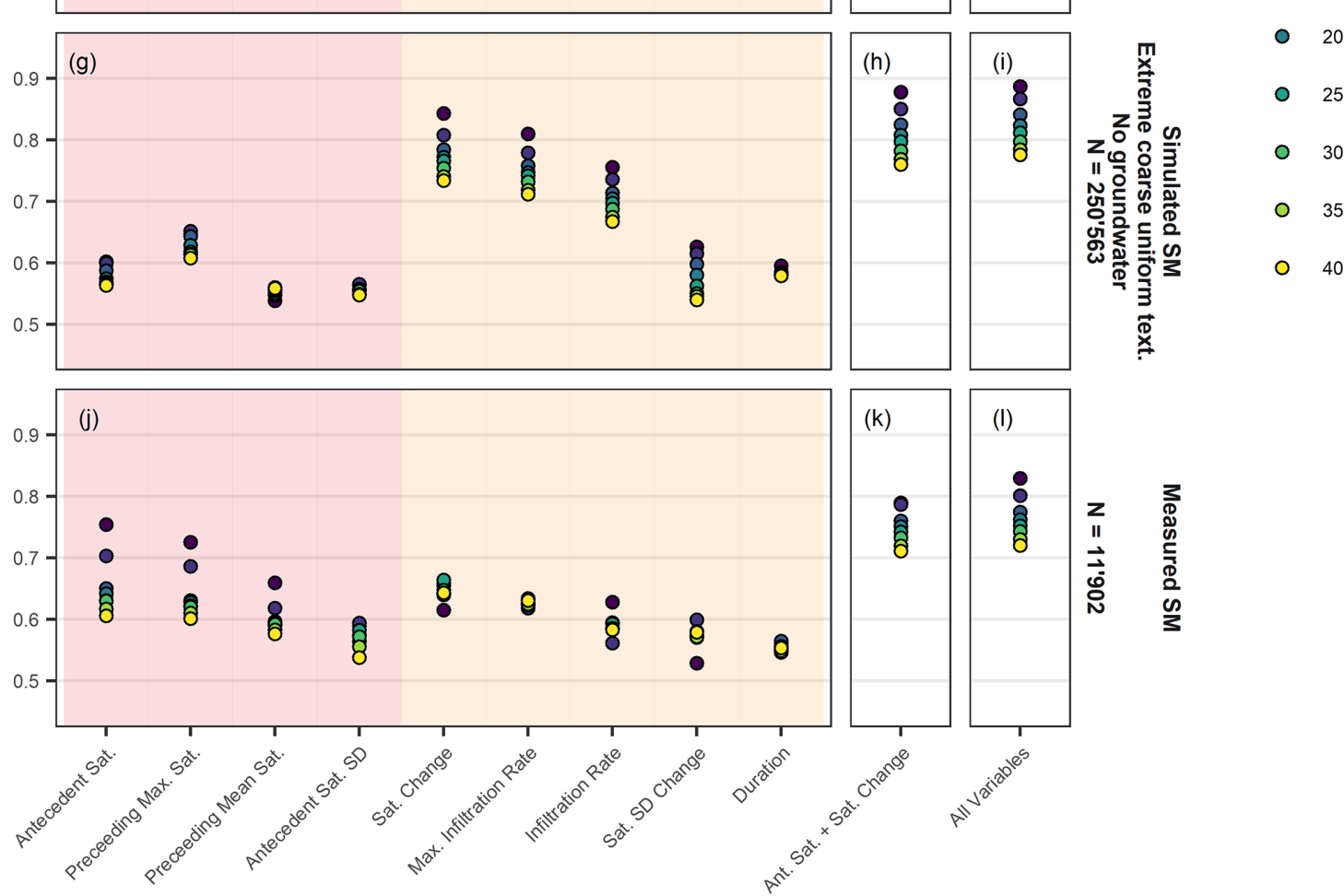

Figure 9. AUC values of model fits based on simulated soil moisture (SM) at all 133 sites (upper three rows) and based on measured soil moisture at the 35 monitoring sites (bottom row). Model fits include individual explanatory variables only (a, d, g, j), the explanatory variables antecedent saturation and saturation change only $(\mathbf{b}, \mathbf{e}, \mathbf{h}, \mathbf{k})$ and all nine explanatory variables $(\mathbf{c}, \mathbf{f}, \mathbf{i}, \mathbf{l})$.

meteorological input data may have a considerable impact if comparing the simulated soil moisture time series with observed soil moisture variation. Particularly rainfall data may lack due to pronounced undercatch problems at high and exposed locations, which were not corrected for in the meteorological time series used in this study (Gergely Rigo, MeteoSwiss, personal communication, 2020).
Following on from this, the goodness of fit might improve significantly by applying a site-specific calibration scheme to better characterize boundary conditions or to derive soil hydrological conditions during the calibration process. While this would allow the reflection of complex local conditions, site-specific calibration is limited by the availability of field data for calibration (e.g. soil moisture or evapotranspiration data) and the quality of these field data, and it is restricted 


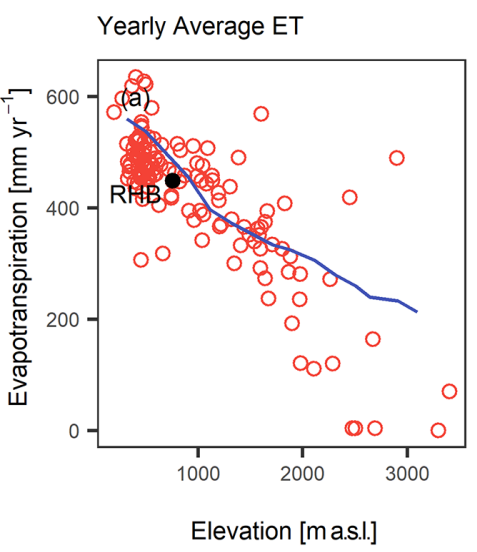

- HADES

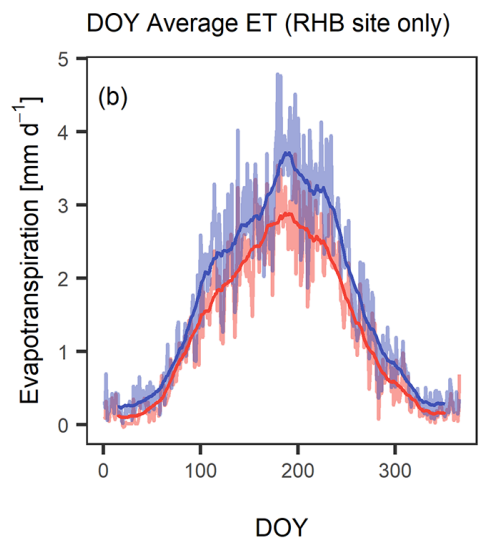

- CoupModel L Lysimeter

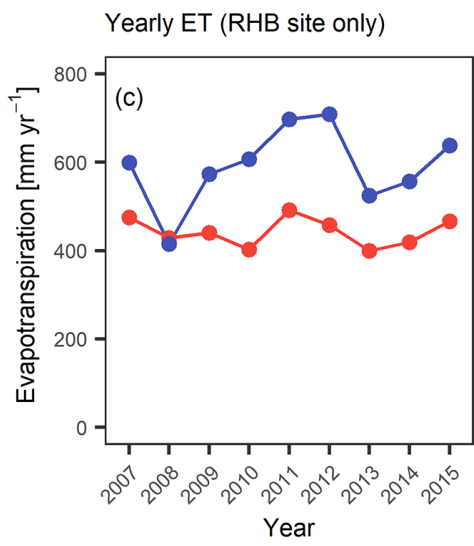

$\longrightarrow$ CoupModel $\longrightarrow$ Lysimeter

Figure 10. Simulated evapotranspiration (ET) from the CoupModel versus validation data. (a) Yearly average ET versus elevation function from the Swiss Hydrological Atlas, (b) day of the year's average ET and (c) yearly ET at the Rietholzbach site (RHB) vs. lysimeter data measured at this site.

by the number of parameters to fit. Furthermore, site-specific calibration is not possible if the model is applied at places where no measurements are available (e.g. for complementing an existing soil moisture monitoring network). Grouping sites into areas of similar physiographic characteristics, e.g. based on soil type, land use or geological data, to further constrain parameter values may be a first step towards this (Fatichi et al., 2016). Furthermore, the use of simpler model formulations with fewer parameters to fit would be worth exploring, as this could help with transferring the model to places where no calibration is possible. Finally, data assimilation techniques, often applied with land surface models (Reichle et al., 2014) or in models used for landslide early warning (Krøgli et al., 2018), could help to adjust for the seasonal misfit of the long-term water storage term, but these again depend on the availability of field data and are, thus, limited to locations with soil moisture measurements.

\subsection{The value of simulated soil moisture for landslide early warning}

Our results showed that the simulation-based landslide forecast models performed slightly better than a forecast model based on soil moisture measurements, implying that simulation-based soil moisture information is, overall, more representative for regional landslide occurrence. This can be explained by considering different timescales and the hydrological processes associated with them. The overall improvement with a simulation-based forecast model is based on a better representation of the triggering conditions, notably the infiltration of water during precipitation or snowmelt events. In this domain, processes typically range in timescales of hours to days and are highly influenced by local factors such as preferential infiltration along macropores and fissures in the ground, surface ponding and runoff due to an impeding surface layer, interception by the vegetation cover, interactions with impeding layers within the soil columns or at the soil-bedrock transition, as well as interactions with a groundwater table. While the spatial variability in these processes can be high in reality, they are simplified and represented homogeneously in the model. In addition to this homogenization in the process domain, the statistical variation is homogenized over time (no sensor errors or drifts as may be observed for single sensors) and between sites (depth levels and number of depth levels considered). We assume that the homogenized representation of the processes in space leads to a more robust statistical model fit and, hence, an improved landslide forecast goodness.

With regard to the antecedent conditions, the measurement-based landslide forecast model performed better. The hydrological processes associated with this domain are governed by the redistribution of soil water after rainfall events by the steady drainage of water at the bottom of the profile and by evapotranspiration from the soil surface. Simplification and misrepresentation of some of these processes in the CoupModel set-up may lead to an underestimation of the seasonal soil moisture variation, which is high in Switzerland, with generally wet conditions from fall to spring and a dry period with intermittent wetting events during summer (Pellet and Hauck, 2017). A limited seasonal representation may reduce the forecast model's ability to separate triggering from nontriggering conditions, as reported for regional landslide forecast models where regions with different seasonal soil moisture variation were compared (Thomas et al., 2020). Particularly in regions with a high seasonal evapotranspiration variation, wet and dry periods may be controlled by different soil moisture fluxes, with vertical fluxes being dominant during dry periods and 


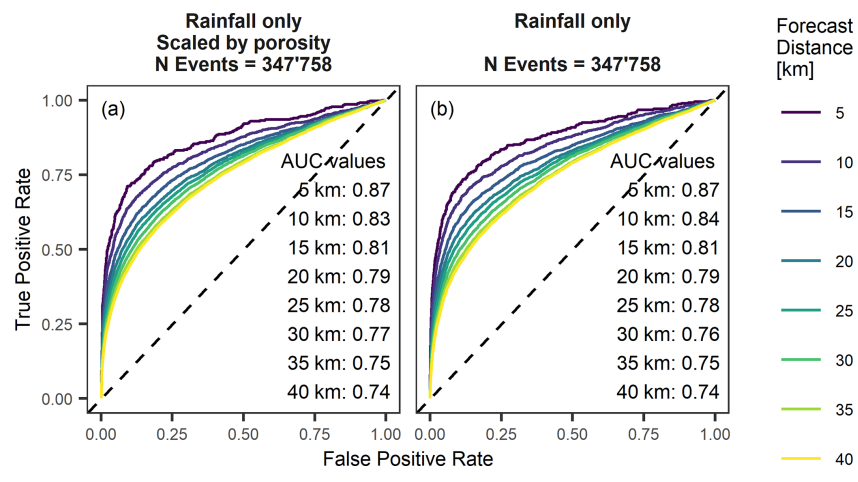

Figure 11. ROC curves and AUC values of model fits (a) based on normalized rainfall information scaled by porosity and (b) based on normalized rainfall information only for all 133 sites and the entire modelling period (1981-2019).

lateral fluxes during wet periods (e.g. Grayson et al., 1997); thus, a physically based representation of the processes is important, and a spatial representation may improve the seasonal soil moisture variation.

While the two process domains (antecedent conditions and event dynamics) can be analysed individually, they also influence each other due to the limited value distribution of soil saturation ranging from $0 \%$ (residual soil water content) to $100 \%$ (full saturation). If water drains quicker, more pore space is available for rainfall to infiltrate in the next event, and intense rainfall events may show a stronger soil moisture response. Conversely, soil moisture responses to precipitation events are weaker in wetter and more fine-grained soils due to slower infiltration, less available pore space due to presaturation and more surface runoff due to impeding conditions near the surface. Hence, in a more conductive soil, the statistical model is more able to separate triggering from nontriggering events at the expense of the loss of long-term water storage information. These effects were most clearly visible when soil hydraulic properties of extremely coarse-grained, uniform texture profiles were used in the CoupModel, which showed an even better landslide forecast goodness. The fast drainage causes the evapotranspiration loss to be ineffective, and thus, the model becomes more a representation of rainfall characteristics demonstrating the high information content in precipitation for landslide prediction.

To validate this hypothesis, we applied the same statistical model to the precipitation time series only, which were used to drive the soil moisture model. Individual precipitation events were defined as continuous periods of rainfall $\left(>0.5 \mathrm{~mm} \mathrm{~h}^{-1}\right)$ separated by gaps of at least $3 \mathrm{~h}$ of no rainfall. Precipitation event sums were computed and (1) normalized with the total porosity of the uppermost $100 \mathrm{~cm}$ taken from SoilGrids, and resulting event sums were normalized with the 99.5 percentile of each time series to represent some soil information (Fig. 11a), or (2) event sums were solely normalized by 99.5 percentile of the event time series (Fig. 11b).
While the first statistical model includes some information on the regional soil physical conditions (porosity from SoilGrids), the latter includes rainfall information only. The number of precipitation events was about double compared to the simulations with soil hydraulic properties (i.e. not all precipitation events were manifested as infiltration events in simulations of soil water dynamics). Despite the larger number of precipitation events (the classification between triggering and nontriggering events is typically easier with a higher number of events), the distance-averaged AUC value dropped from 0.82 for simulations of soil water dynamics to 0.79 for rainfall signatures. But both approaches (based on precipitation and infiltration events, respectively) showed similar landslide forecast goodness and similar forecast distance dependence, highlighting that the landslide forecast goodness is mainly driven by spatial rainfall variation.

While it is discouraging that similar landslide forecast goodness can be achieved with a forecast model that is based on rainfall information only or with a heavily simplified model representation (e.g. based on the extreme, coarsegrained, uniform texture profiles), the benefit of a wellparameterized physically based soil moisture transfer model or of using soil moisture measurements remains in the quantification of the antecedent wetness conditions, particularly if a strong seasonal variation persists. This is often missed by less physically based approaches using, e.g., antecedent wetness indexes or antecedent precipitation indexes (e.g. Brocca et al., 2012). The added value of soil wetness information was tested by comparing a landslide forecast model based on rainfall amounts only (Fig. 12a) with a forecast model based on a combination of rainfall amounts and antecedent saturation derived from measured soil moisture (Fig. 12b) or derived from simulated soil moisture (Fig. 12c). Forecast goodness increase was found for both cases where antecedent saturation was added to the model, demonstrating the information content of soil wetness information. However, the extent of improvement was only minor if simulated soil moisture was added, which can be explained by the described and discussed underrepresentation of the seasonal soil moisture cycle of the soil moisture model that was used.

\section{Conclusions}

The present analysis demonstrated a high information content of simulated soil moisture for regional landslide activity, which was even higher than when in situ soil moisture measurements were used. The forecast goodness of such a landslide warning system strongly depends on the distance between soil moisture stations and landslide location, i.e. on the soil moisture station density, because of more robust model fits at near-forecast distances and a greater spatial coverage of landslide events and regions of interest. The advantage of soil moisture simulations over in situ soil moisture measurements is the better representation of trigger- 

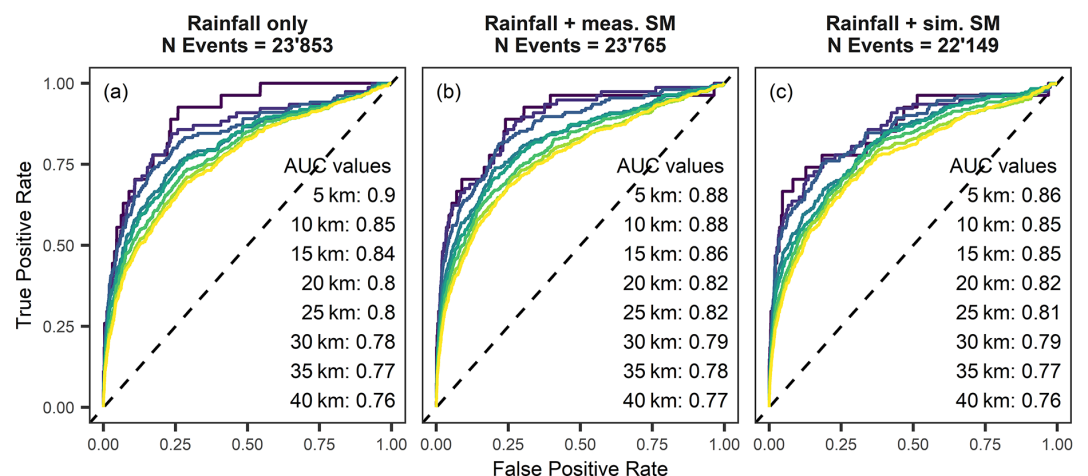

Forecast

[km]

[km]

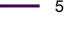

$-10$

$\longrightarrow \quad 15$

$-20$

$-25$

$-30$

$\longrightarrow 35$

Figure 12. ROC curves and AUC values of model fits (a) based on normalized rainfall information only, (b) based on normalized rainfall and measured antecedent saturation and (c) based on normalized rainfall and simulated antecedent saturation for all 35 monitoring sites and the period of 2008 to 2019 .

ing event conditions, probably due to the homogenization of the hydrological processes and the site representation (number and depths of sensors included). On the other hand, the simulation-based forecast model performed worse than the measurement-based model at reproducing critical antecedent saturation conditions, possibly due to the inadequate representation of the long-term water storage.

In comparison with a statistical landslide forecast model that only uses precipitation or that simulates soil moisture with very simplified (uniform) soil hydraulic properties, the main added value of a comprehensive physically based soil moisture simulation is the representation of critical antecedent wetness conditions. To improve the soil moisture model in this respect, further explorations in the use of siteor region-specific calibration schemes are needed, and calibration data other than soil moisture measurements should be incorporated. 


\section{Appendix A}

Table A1. Key equations of the CoupModel used for this study (see Jansson and Karlberg, 2011, for more details).

\begin{tabular}{|c|c|c|}
\hline No. & Equation & Description \\
\hline \multicolumn{3}{|c|}{ Deep percolation (unsaturated conditions) } \\
\hline (A1) & $q_{\text {deep }}= \begin{cases}k_{\text {wlow }}, & \psi>\psi_{\text {Max }} \\
0, & \psi \leq \psi_{\text {Max }}\end{cases}$ & $\begin{array}{l}\text { Deep percolation, } q_{\text {deep }} \text {, under unsaturated conditions as a func- } \\
\text { tion of the hydraulic conductivity of the lowest layer, } k_{\text {wlow }} \text {, and } \\
\text { the simulated pressure head of the lowest layer, } \psi \text {. Deep perco- } \\
\text { lation occurs if the maximum pressure head, } \psi_{\mathrm{Max}} \text {, is exceeded. } \\
\text { Below the threshold, no flow of water occurs. }\end{array}$ \\
\hline
\end{tabular}

Deep percolation (saturated conditions)

(A2) $\quad q_{\text {deep }}=\frac{8 k_{\text {slow }}\left(z_{\text {sat }}-z_{p 2}\right)^{2}}{d_{p 2}^{2}}$

Saturated deep percolation $\left(q_{\text {deep }}\right)$ depends on the saturated hydraulic conductivity of the lowest layer $\left(k_{\text {slow }}\right)$. Drainage is at a spacing distance $\mathrm{d}_{p 2}$ and at depth $\mathrm{z}_{p 2}$, both of which are parameters. The simulated groundwater table depth is at $z_{\text {sat }}$.

Infiltration and surface runoff

(A3) $\quad q_{\text {in }}= \begin{cases}q_{\text {th }}, & i_{\text {cap }}>q_{\text {th }} \\ i_{\text {cap }}, & i_{\text {cap }} \leq q_{\text {th }}\end{cases}$

The infiltration rate $\left(q_{\text {in }}\right)$ is simulated as a function of the surface infiltration capacity $\left(i_{\text {cap }}\right)$. It equals the precipitation throughfall rate $\left(q_{\text {th }}\right)$ if the throughfall is smaller than the infiltration rate.

(A4) $q_{\text {surf }}= \begin{cases}a_{\text {surf }}\left(W_{\text {pool }}-w_{\text {pmax }}\right), & W_{\text {pool }}>w_{\text {pmax }} \\ 0, & W_{\text {pool }} \leq w_{\text {pmax }}\end{cases}$

Surface runoff $\left(q_{\text {surf }}\right)$ is generated if throughfall exceeds the infiltration capacity and a surface pool of water is formed, with $W_{\text {pool }}$ being the total water amount. The amount of water which can be stored ( $\left.w_{\text {pmax }}\right)$ is a parameter and $a_{\text {surf }}$ is an empirical coefficient.

Potential transpiration

(A5) $\quad L_{\mathrm{v}} E_{\mathrm{tp}}=\frac{\Delta \mathrm{R}_{\mathrm{n}}+\rho_{\mathrm{a}} c_{p} \frac{\left(e_{\mathrm{s}}-e_{\mathrm{a}}\right)}{r_{\mathrm{a}}}}{\Delta+\gamma\left(1+\frac{r_{\mathrm{s}}}{r_{\mathrm{a}}}\right)}$

The Penman's combination equation (Monteith, 1965) is used to calculate potential transpiration $\left(E_{\mathrm{tp}}\right)$. It depends on net radiation $\left(R_{\mathrm{n}}\right)$, the difference in saturation and actual vapour pressure $\left(e_{\mathrm{S}}-e_{\mathrm{a}}\right)$, the aerodynamic resistance $\left(r_{\mathrm{a}}\right)$ and the surface resistance $\left(r_{\mathrm{s}}\right)$. It further depends on air density $\left(\rho_{\mathrm{a}}\right)$, specific heat of air $\left(c_{p}\right)$, latent heat of vaporization $\left(L_{\mathrm{V}}\right)$ and the psychometric constant $(\gamma)$, which are all considered physical constants, and the slope of saturated vapour pressure vs. the temperature curve $(\Delta)$.

(A6) $\quad r_{\mathrm{a}}=\frac{\ln ^{2}\left(\frac{z_{\mathrm{ref}}-d}{z_{0}}\right)}{\mathrm{k}^{2} u}$

The aerodynamic resistance $\left(r_{\mathrm{a}}\right)$ depends on the wind speed $(u)$ measured at the reference height $\left(z_{\text {ref }}\right)$. It is proportional to the displacement height $(d)$ and inversely proportional to the roughness length $\left(z_{0}\right)$. $\mathrm{k}$ is the von Karman's constant.

(A7) $\quad r_{\mathrm{s}}=\frac{1}{\max \left(A_{1} g_{1}, 0.001\right)}$ Surface resistance $\left(r_{\mathrm{S}}\right)$ inversely proportional to the leaf area index $\left(A_{1}\right)$ and the leaf conductance $\left(g_{1}\right)$.

(A8) $\quad g_{1}=\frac{R_{\mathrm{is}}}{R_{\mathrm{is}}+g_{\text {ris }}} \frac{g_{\max }}{1+\frac{\left(e_{\mathrm{s}}-e_{\mathrm{a}}\right)}{g_{\mathrm{vpd}}}}$

The leaf conductance $\left(g_{1}\right)$ is calculated by the Lohammar equation (Lindroth, 1985; Lohammar et al., 1980). It depends on global radiation $\left(R_{\mathrm{is}}\right)$ and the vapour pressure deficit $\left(e_{\mathrm{s}}-e_{\mathrm{a}}\right)$, with $g_{\text {ris }}, g_{\max }$ and $g_{\text {vpd }}$ being parameter values. 
Table A1. Continued.

\begin{tabular}{lll}
\hline No. Equation & Description \\
\hline Actual transpiration & \\
\hline (A9) $\quad E_{\mathrm{ta}}=E_{\mathrm{ta}}{ }^{*}+f_{\mathrm{umov}}\left(E_{\mathrm{tp}}{ }^{*}-E_{\mathrm{ta}}{ }^{*}\right)$ & $\begin{array}{l}\text { Actual transpiration }\left(E_{\mathrm{ta}}\right) \text { may compensate for soil layers with } \\
\text { water stress by a two-step calculation. The left term }\left(E_{\mathrm{ta}}{ }^{*}\right) \text { cor- } \\
\text { responds to the water uptake without compensation. The right } \\
\text { term is the difference of the potential transpiration }\left(E_{\mathrm{tp}}{ }^{*}, \text { with }\right.\end{array}$ \\
& $\begin{array}{l}\text { a reduction due to interception evapotranspiration }) \text { and actual } \\
\text { transpiration, and the degree of compensation is governed by } \\
\text { the parameter } f_{\mathrm{umov}} .\end{array}$ \\
\end{tabular}

(A10) $\quad E_{\mathrm{ta}} *=E_{\mathrm{tp}} * \int_{z_{\mathrm{r}}}^{0} f(\psi(z)) f(T(z)) r(z)$

Response functions for soil water potential, $f(\psi(z))$, and for soil temperature, $f(T(z))$, are used to reduce potential transpiration $\left(E_{\mathrm{tp}}{ }^{*}\right)$ to calculate actual transpiration $\left(E_{\mathrm{ta}}{ }^{*}\right)$. It is calculated for each soil layer and integrated, with $r(z)$ being the distribution of relative root density and $z_{\mathrm{r}}$ being the maximal root depth.

(A11) $f(\psi(z))=\min \left(\left(\frac{\psi_{\mathrm{c}}}{\psi(z)}\right)^{p_{1} E_{\mathrm{tp}}+p_{2}}, f_{\theta}\right)$

Transpiration is reduced under dry conditions by stomatal mechanism and xylary tissue resistance and becomes zero at the wilting point. $p_{1}, p_{2}$ and $\psi_{\mathrm{c}}$ are parameters, and $f_{\theta}$ is an additional response function (not shown).

(A12) $\int_{z_{\mathrm{r}}}^{z} r(z)=\frac{1-e^{-k_{\mathrm{rr}}\left(z / z_{\mathrm{r}}\right)}}{\left(1-r_{\mathrm{frac}}\right)}$

The distribution of root density is represented in exponential form. Below a depth $z$, the fraction of roots depends on the extinction coefficient $k_{\mathrm{rr}}$, whereas $r_{\text {frac }}$ is a parameter. The integral calculated on the entire soil profile equals unity.

Soil evaporation

$$
L_{\mathrm{V}} E_{\mathrm{S}}=\frac{\Delta\left(R_{\mathrm{ns}}-q_{\mathrm{h}}\right)+\rho_{\mathrm{a}} c_{p} \frac{\left(e_{\mathrm{s}}-e_{\mathrm{a}}\right)}{r_{\mathrm{as}}}}{\Delta+\gamma\left(1+\frac{r_{\mathrm{ss}}}{r_{\mathrm{as}}}\right)}
$$

The Penman's equation (Monteith, 1965) is used for the calculation of soil evaporation $\left(E_{\mathrm{S}}\right)$. It is calculated from the surface latent heat flux $\left(L_{\mathrm{V}} E_{\mathrm{S}}\right)$ which depends on the energy available at the surface $\left(R_{\mathrm{ns}}-q_{\mathrm{h}}\right.$, i.e. available net radiation minus soil surface heat flux from previous step), the aerodynamic resistance $\left(r_{\mathrm{as}}\right)$, the surface resistance $\left(r_{\mathrm{Ss}}\right)$, and the difference in saturation and actual vapour pressure $\left(e_{\mathrm{s}}-e_{\mathrm{a}}\right)$. All other terms are equal to the terms in (A5).

(A14) $r_{\mathrm{ss}}=\max \left(0, r_{\psi 1} \max \left(\psi_{\mathrm{s}}-r_{\psi 2}, 0\right)-r_{\psi 3} \delta_{\text {surf }}\right)$ Soil surface resistance $\left(\mathrm{r}_{\mathrm{sS}}\right)$ is governed by the parameters $r_{\psi 1}$, $r_{\psi_{2}}$ and $r_{\psi 3}$. It accounts for the water tension in the uppermost layer $\left(\psi_{\mathrm{s}}\right)$ and the mass balance at the soil surface $\left(\delta_{\text {surf }}\right)$.

Radiation processes

\begin{tabular}{lll}
\hline (A15) $\quad R_{\mathrm{n}, \mathrm{tot}}=R_{\mathrm{iS}}\left(1-a_{\mathrm{r}}\right)+R_{\text {lnet }}$ & $\begin{array}{l}\text { Net radiation }\left(R_{\mathrm{n}, \text { tot }}\right) \text { is the sum of global radiation }\left(R_{\mathrm{is}}\right) \text { minus } \\
\text { the surface albedo }\left(a_{\mathrm{r}}\right) \text {, and net long-wave radiation }\left(R_{\text {lnet }}\right) .\end{array}$ \\
\hline (A16) $\quad R_{\text {lnet }}=86400 \sigma\left(\varepsilon_{\mathrm{S}}\left(T_{\mathrm{S}}+273.15\right)^{4}-\varepsilon_{\mathrm{a}}\left(T_{\mathrm{a}}+273.15\right)^{4}\right)$ & $\begin{array}{l}\text { The Brunt's formula is used to calculate net long-wave ra- } \\
\text { diation }\left(R_{\text {lnet }}\right) \text {, where the surface emissivity }\left(\varepsilon_{\mathrm{S}}\right) \text { is assumed } \\
\text { equal to } 1 \text {, and the atmosphere emissivity }\left(\varepsilon_{\mathrm{a}}\right) \text { is calculated by } \\
\text { Konzelmann et al. (1994). } T_{\mathrm{S}} \text { is the surface temperature. }\end{array}$
\end{tabular}


Table A1. Continued.

\begin{tabular}{|c|c|c|}
\hline No. & Equation & Description \\
\hline (A17) & $P_{\text {rain }}=P\left(1-Q_{\mathrm{p}}\right)$ & $\begin{array}{l}\text { The fraction of solid precipitation }\left(Q_{\mathrm{p}}\right) \text { determines } \\
\text { the snow and rain partitioning of precipitation }(P) \text {. }\end{array}$ \\
\hline (A18) & $Q_{\mathrm{p}}= \begin{cases}\min \left(1,\left(1-f_{\text {liqmax }}\right)+f_{\text {liqmax }} \frac{T_{\mathrm{a}}-T_{\text {RainL }}}{T_{\text {SnowL }}-T_{\text {RainL }}}\right), & T_{\mathrm{a}} \leq T_{\text {RainL }} \\
0, & T_{\mathrm{a}}>T_{\text {RainL }}\end{cases}$ & $\begin{array}{l}Q_{\mathrm{p}} \text { is a function of air temperature }\left(T_{\mathrm{a}}\right) \text {, with } \\
T_{\mathrm{RainL}} \text { and } T_{\text {SnowL }} \text { being parameters describing the } \\
\text { temperature range of mixed ice and liquid water } \\
\text { precipitation and } f_{\text {liqmax }} \text { being the maximal liquid } \\
\text { water content of falling snow (equals } 0.5 \text { ). }\end{array}$ \\
\hline (A19) & $M=M_{T} T_{\mathrm{a}}+M_{\mathrm{R}} R_{\mathrm{is}}+\frac{f_{q \mathrm{~h}} q_{\mathrm{h}}(0)}{L_{\mathrm{f}}}$ & $\begin{array}{l}\text { Snowmelt }(M) \text { is calculated from a temperature } \\
\text { function }\left(M_{T}\right) \text { and air temperature }\left(T_{\mathrm{a}}\right) \text {, a solar ra- } \\
\text { diation function }\left(M_{\mathrm{R}}\right) \text { and global radiation }\left(R_{\mathrm{is}}\right) \text {, as } \\
\text { well as from surface heat flow }\left(q_{\mathrm{h}}\right) \text {, a scaling coef- } \\
\text { ficient }\left(f_{q \mathrm{~h}}\right) \text { and the latent heat of freezing }\left(L_{\mathrm{f}}\right) \text {. }\end{array}$ \\
\hline \multicolumn{3}{|c|}{ Soil heat flow } \\
\hline (A21) & $q_{\mathrm{h}}=-k_{\mathrm{h}} \frac{\partial T}{\partial z}+C_{\mathrm{w}} T q_{\mathrm{w}}$ & $\begin{array}{l}\text { Soil heat flow }\left(q_{\mathrm{h}}\right) \text { is calculated as the sum of con- } \\
\text { duction (first term) and convection (second term), } \\
\text { where } k_{\mathrm{h}} \text { is the soil heat conductivity, } T \text { is temper- } \\
\text { ature, } C_{\mathrm{w}} \text { is heat capacity of liquid water and } q_{\mathrm{w}} \\
\text { is the liquid water flow. In this model set-up, latent } \\
\text { heat flow by water vapour was disregarded. }\end{array}$ \\
\hline
\end{tabular}


Table A2. Description of the most important parameter values used in the CoupModel set-up along with the associated equations (see Jansson and Karlberg, 2011, for more details).

\begin{tabular}{|c|c|c|c|c|}
\hline Symbol & Description & Unit & Value & Eq. \\
\hline \multicolumn{5}{|c|}{ Deep percolation, unsaturated conditions } \\
\hline$\psi_{\text {Max }}$ & Maximum pressure head in lowest layer above which outflow occurs & $\mathrm{cm}$ & 10 & (A1) \\
\hline \multicolumn{5}{|c|}{ Deep percolation, saturated conditions } \\
\hline$z_{p 2}$ & Drain level depth & $\mathrm{m}$ & 7.5 & (A2) \\
\hline$d_{p 2}$ & Spacing distance to drain & $\mathrm{m}$ & 100 & (A2) \\
\hline \multicolumn{5}{|c|}{ Infiltration and surface runoff } \\
\hline$a_{\text {surf }}$ & Empirical coefficient used to calculate runoff from surface pool & $1 \mathrm{~d}^{-1}$ & 0.8 & (A4) \\
\hline$w_{\text {pmax }}$ & Maximum water amount stored in surface pool. & $\mathrm{mm}$ & 0 & (A4) \\
\hline \multicolumn{5}{|c|}{ Potential transpiration } \\
\hline$z_{0}$ & Roughness length & - & 0.1 & (A6) \\
\hline$d$ & Displacement height & - & 0.66 & (A6) \\
\hline$z_{\text {ref }}$ & Height above ground of wind speed, air humidity and air temperature measurements & $\mathrm{m}$ & 2 & (A6) \\
\hline$A_{1}$ & Leaf area index & $\mathrm{m}^{2} \mathrm{~m}^{-2}$ & 0.6 & (A7) \\
\hline$g_{\text {ris }}$ & Global radiation intensity at which light response is at half-light saturation & $\mathrm{J} \mathrm{m}^{-2} \mathrm{~d}^{-1}$ & $5 e+6$ & (A8) \\
\hline$g_{\max }$ & Maximum conductance of fully open stomata & $\mathrm{ms}^{-1}$ & 0.03 & (A8) \\
\hline$g_{\text {vpd }}$ & Vapour pressure deficit at which stomatal conductance is reduced by $50 \%$ & $\mathrm{~Pa}$ & 100 & (A8) \\
\hline \multicolumn{5}{|c|}{ Actual transpiration } \\
\hline$f_{\text {umov }}$ & Degree of compensation for compensatory water uptake & - & 0.6 & (A10) \\
\hline$z_{\mathrm{r}}$ & Maximum rooting depth & $\mathrm{m}$ & -0.6 & (A10) \\
\hline$p_{1}$ & Empirical coefficient for soil water potential response function & $1 \mathrm{~d}^{-1}$ & 0.3 & (A11) \\
\hline$p_{2}$ & Empirical coefficient for soil water potential response function & $\mathrm{kg} \mathrm{m}^{-2} \mathrm{~d}^{-1}$ & 0.1 & (A11) \\
\hline$\psi_{\mathrm{c}}$ & Pressure head above which potential water uptake is reduced & $\mathrm{cm}$ water & 1500 & (A11) \\
\hline$r_{\text {frac }}$ & Fraction of roots remaining below a given root depth & - & 0.1 & (A12) \\
\hline \multicolumn{5}{|c|}{ Soil evaporation } \\
\hline$r_{\psi 1}$ & Governing parameter for the calculation of the surface resistance & $\mathrm{s} \mathrm{m}^{-1}$ & 0.5 & (A14) \\
\hline$r_{\psi 2}$ & Governing parameter for the calculation of the surface resistance & $\mathrm{sm}^{-1}$ & 300 & (A14) \\
\hline$r_{\psi 3}$ & Governing parameter for the calculation of the surface resistance & $\mathrm{s} \mathrm{m}^{-1} \mathrm{~mm}^{-1}$ & 80 & (A14) \\
\hline \multicolumn{5}{|c|}{ Snow dynamics } \\
\hline$T_{\text {RainL }}$ & Temperature above which all precipitation is rain & ${ }^{\circ} \mathrm{C}$ & 2 & (A18) \\
\hline$T_{\text {SnowL }}$ & Temperature below which all precipitation is snow & ${ }^{\circ} \mathrm{C}$ & 0 & (A18) \\
\hline$f_{q \mathrm{~h}}$ & Contribution coefficient of ground heat flow on snowmelt & - & 0.5 & (A19) \\
\hline$m_{T}$ & Temperature coefficient for snowmelt calculation & $\mathrm{kg}^{\circ} \mathrm{C}^{-1} \mathrm{~m}^{-2} \mathrm{~d}^{-1}$ & 1.5 & (A20) \\
\hline$m_{\mathrm{f}}$ & Efficiency constant for refreezing calculation & $\mathrm{m}^{-1}$ & 0.1 & (A20) \\
\hline
\end{tabular}


Code and data availability. The meteorological, soil moisture and landslide data were kindly provided by the cited institutions; the CoupModel can be downloaded from https://www.coupmodel.com/ (Jansson, 2021). The lysimeter validation data were taken from Hirschi et al. (2018; https://doi.org/10.3929/ethz-b-000282395).

Author contributions. AW carried out the soil moisture simulations and statistical analysis and wrote the paper. PEJ provided guidance for the soil moisture simulations. PL contributed to the preparation of the soil hydrological properties. $\mathrm{CH}$ and MS supervised the work. All co-authors provided guidance on the paper's research and contributed to the paper.

Competing interests. The authors declare that they have no conflict of interest.

Disclaimer. Publisher's note: Copernicus Publications remains neutral with regard to jurisdictional claims in published maps and institutional affiliations.

Acknowledgements. This research project is part of the programme Climate Change Impacts on Alpine Mass Movements of the Swiss Federal Research Institute WSL. We thank MeteoSwiss, Joachim Schung (DTN), Matthias Häni and Peter Waldner (both from LWF), Sabina Keller (Swiss FluxNet) and Sonia I. Seneveriatne and Martin Hirschi (Land-Climate Dynamics group of ETH Zurich) for providing the meteorological input data, as well as soil moisture data, for this study. We thank Roberto Greco and two anonymous reviewers for their constructive comments towards improving the paper.

Financial support. This research has been supported by the Schweizerischer Nationalfonds zur Förderung der Wissenschaftlichen Forschung (grant no. 175785).

Review statement. This paper was edited by Nunzio Romano and reviewed by Roberto Greco and one anonymous referee.

\section{References}

Aleotti, P.: A warning system for rainfall-induced shallow failures, Eng. Geol., 73, 247-265, https://doi.org/10.1016/j.enggeo.2004.01.007, 2004.

Anagnostopoulos, G. G., Fatichi, S., and Burlando, P.: An advanced process-based distributed model for the investigation of rainfall-induced landslides: The effect of process representation and boundary conditions, Water Resour. Res., 51, 7501-7523, https://doi.org/10.1002/2015WR016909, 2015.

Babaeian, E., Sadeghi, M., Jones, S. B., Montzka, C., Vereecken, H., and Tuller, M.: Ground, Proximal and Satellite Remote Sensing of Soil Moisture, Rev. Geophys., 57, 2018RG000618, https://doi.org/10.1029/2018RG000618, 2019.
Baum, R. L., Godt, J. W., and Savage, W. Z.: Estimating the timing and location of shallow rainfall-induced landslides using a model for transient, unsaturated infiltration, J. Geophys. Res, 115, 3013, https://doi.org/10.1029/2009JF001321, 2010.

Bogaard, T. and Greco, R.: Invited perspectives: Hydrological perspectives on precipitation intensity-duration thresholds for landslide initiation: proposing hydro-meteorological thresholds, Nat. Hazards Earth Syst. Sci., 18, 31-39, https://doi.org/10.5194/nhess-18-31-2018, 2018.

Bogaard, T. A. and Greco, R.: Landslide hydrology: from hydrology to pore pressure, WIRES Water, 3, 439-459, https://doi.org/10.1002/wat2.1126, 2016.

Bordoni, M., Vivaldi, V., Lucchelli, L., Ciabatta, L., Brocca, L., Galve, J. P., and Meisina, C.: Development of a data-driven model for spatial and temporal shallow landslide probability of occurrence at catchment scale, Landslides, 18, 1209-1229, https://doi.org/10.1007/s10346-020-01592-3, 2020.

Brocca, L., Melone, F., and Moramarco, T.: On the estimation of antecedent wetness conditions in rainfall-runoff modelling, Hydrol. Process., 22, 629-642, https://doi.org/10.1002/hyp.6629, 2008.

Brocca, L., Ponziani, F., Moramarco, T., Melone, F., Berni, N., and Wagner, W.: Improving landslide forecasting using ASCATderived soil moisture data: A case study of the torgiovannetto landslide in central Italy, Remote Sens., 4, 1232-1244, https://doi.org/10.3390/rs4051232, 2012.

Brocca, L., Ciabatta, L., Moramarco, T., Ponziani, F., Berni, N., and Wagner, W.: Use of Satellite Soil Moisture Products for the Operational Mitigation of Landslides Risk in Central Italy, in: Satellite Soil Moisture Retrieval, 231-247, Elsevier, Amsterdam, 2016.

Buckingham, E.: Studies on the movement of soil moisture, Bull. No. 38, US Dep. Agric. Bur. Soils, Washington, 1907.

Caine, N.: The Rainfall Intensity - Duration Control of Shallow Landslides and Debris Flows, Geogr. Ann. Ser. A, Phys. Geogr., 62, 23-27, https://doi.org/10.1080/04353676.1980.11879996, 1980.

CH2018: CH2018 - Climate Scenarios for Switzerland, Technical Report, National Centre for Climate Services, Zurich, 2018.

Christiansen, J. R., Elberling, B., and Jansson, P. E.: Modelling water balance and nitrate leaching in temperate Norway spruce and beech forests located on the same soil type with the CoupModel, For. Ecol. Manage., 237, 545-556, https://doi.org/10.1016/j.foreco.2006.09.090, 2006.

Conrad, Y. and Fohrer, N.: Application of the Bayesian calibration methodology for the parameter estimation in CoupModel, Adv. Geosci., 21, 13-24, https://doi.org/10.5194/adgeo-21-132009, 2009.

Crozier, M. J.: Prediction of rainfall-triggered landslides: a test of the Antecedent Water Status Model, Earth Surf. Process. Landforms, 24, 825-833, https://doi.org/10.1002/(SICI)10969837(199908)24:9<825::AID-ESP14>3.0.CO;2-M, 1999.

Fatichi, S., Ivanov, V. Y., and Caporali, E.: A mechanistic ecohydrological model to investigate complex interactions in cold and warm water-controlled environments: 1 . Theoretical framework and plot-scale analysis, J. Adv. Model. Earth Syst., 4, 1-31, https://doi.org/10.1029/2011MS000086, 2012.

Fatichi, S., Vivoni, E. R., Ogden, F. L., Ivanov, V. Y., Mirus, B., Gochis, D., Downer, C. W., Camporese, M., Davison, J. H., Ebel, B., Jones, N., Kim, J., Mascaro, G., Niswonger, R., Re- 
strepo, P., Rigon, R., Shen, C., Sulis, M., and Tarboton, D.: An overview of current applications, challenges, and future trends in distributed process-based models in hydrology, J. Hydrol., 537, 45-60, https://doi.org/10.1016/j.jhydrol.2016.03.026, 2016.

Fatichi, S., Or, D., Walko, R., Vereecken, H., Young, M. H., Ghezzehei, T. A., Hengl, T., Kollet, S., Agam, N., and Avissar, R.: Soil structure is an important omission in Earth System Models, Nat. Commun., 11, 522, https://doi.org/10.1038/s41467-020-14411z, 2020 .

Fawcett, T.: An introduction to ROC analysis, Pattern Recognit. Lett., 27, 861-874, https://doi.org/10.1016/j.patrec.2005.10.010, 2006.

Feddes, R. A., Kabat, P., Van Bakel, P. J. T., Bronswijk, J. J. B., and Halbertsma, J.: Modelling soil water dynamics in the unsaturated zone - State of the art, J. Hydrol., 100, 69-111, https://doi.org/10.1016/0022-1694(88)90182-5, 1988.

Froude, M. J. and Petley, D. N.: Global fatal landslide occurrence from 2004 to 2016, Nat. Hazards Earth Syst. Sci., 18, 2161-2181, https://doi.org/10.5194/nhess-18-2161-2018, 2018.

Gharari, S., Hrachowitz, M., Fenicia, F., Gao, H., and Savenije, H. H. G.: Using expert knowledge to increase realism in environmental system models can dramatically reduce the need for calibration, Hydrol. Earth Syst. Sci., 18, 4839-4859, https://doi.org/10.5194/hess-18-4839-2014, 2014.

Glade, T.: Modelling landslide-triggering rainfalls in different regions of New Zealand - the soil water status model, Z. Geomorphol., 122, 63-84, 2000.

Godt, J. W., Baum, R. L., and Chleborad, A. F.: Rainfall characteristics for shallow landsliding in Seattle, Washington, USA, Earth Surf. Process. Landforms, 31, 97-110, https://doi.org/10.1002/esp.1237, 2006.

Grayson, R. B., Western, A. W., Chiew, F. H. S., and Blöschl, G.: Preferred states in spatial soil moisture patterns: Local and nonlocal controls, Water Resour. Res., 33, 2897-2908, https://doi.org/10.1029/97WR02174, 1997.

Gupta, H. V. and Nearing, G. S.: Debates-the future of hydrological sciences: A (common) path forward? Using models and data to learn: A systems theoretic perspective on the future of hydrological science, Water Resour. Res., 50, 5351-5359, https://doi.org/10.1002/2013WR015096, 2014.

Guzzetti, F., Peruccacci, S., Rossi, M., and Stark, C. P.: The rainfall intensity-duration control of shallow landslides and debris flows: An update, Landslides, 5, 3-17, https://doi.org/10.1007/s10346007-0112-1, 2008.

Guzzetti, F., Gariano, S. L., Peruccacci, S., Brunetti, M. T., Marchesini, I., Rossi, M., and Melillo, M.: Geographical landslide early warning systems, Earth-Sci. Rev., 200, 102973, https://doi.org/10.1016/j.earscirev.2019.102973, 2020.

Harlan, R. L.: Analysis of coupled heat-fluid transport in partially frozen soil, Water Resour. Res., 9, 1314-1323, https://doi.org/10.1029/WR009i005p01314, 1973.

He, H., Jansson, P. E., Svensson, M., Meyer, A., Klemedtsson, L., and Kasimir, A.: Factors controlling Nitrous Oxide emission from a spruce forest ecosystem on drained organic soil, derived using the CoupModel, Ecol. Modell., 321, 46-63, https://doi.org/10.1016/j.ecolmodel.2015.10.030, 2016.

Hengl, T., Mendes de Jesus, J., Heuvelink, G. B. M., Ruiperez Gonzalez, M., Kilibarda, M., Blagotić, A., Shangguan, W., Wright, M. N., Geng, X., Bauer-Marschallinger, B., Guevara, M. A.,
Vargas, R., MacMillan, R. A., Batjes, N. H., Leenaars, J. G. B., Ribeiro, E., Wheeler, I., Mantel, S., and Kempen, B.: SoilGrids250m: Global gridded soil information based on machine learning, edited by B. Bond-Lamberty, PLoS One, 12, e0169748, https://doi.org/10.1371/journal.pone.0169748, 2017.

Hess, J., Rickli, C., McArdell, B., and Stähli, M.: Investigating and Managing Shallow Landslides in Switzerland, in: Landslide Science for a Safer Geoenvironment, edited by: Sassa, K., Canuti, P., and Yin, Y., 805-808, Springer, Cham, 2014.

Hilker, N., Badoux, A., and Hegg, C.: The Swiss flood and landslide damage database 1972-2007, Nat. Hazards Earth Syst. Sci., 9, 913-925, https://doi.org/10.5194/nhess-9-913-2009, 2009.

Hirschi, M., Michel, D., Lehner, I., and Seneviratne, S. I.: A sitelevel comparison of lysimeter and eddy covariance flux measurements of evapotranspiration, Hydrol. Earth Syst. Sci., 21, 18091825, https://doi.org/10.5194/hess-21-1809-2017, 2017.

Hirschi, M., Michel, D., Lehner, I., and Seneviratne, S. I.: Rietholzbach catchment data, ETH Zurich [data set], https://doi.org/10.3929/ethz-b-000282395, 2018.

Hungr, O., Leroueil, S., and Picarelli, L.: The Varnes classification of landslide types, an update, Landslides, 11, 167-194, https://doi.org/10.1007/s10346-013-0436-y, 2014.

Jansson, P.-E.: CoupModel - Coupled heat and mass transfer model for the soil-plant-atmosphere system, available at: https://www. coupmodel.com/, last access: 21 July 2021.

Jansson, P.-E.: CoupModel: Model Use, Calibration, and Validation, Trans. ASABE, 55, 1337-1346, https://doi.org/10.13031/2013.42245, 2012.

Jansson, P.-E. and Karlberg, L. (Eds.): Coupled heat and mass transfer model for soil-plant-atmosphere systems. COUP Manual., Department of Civil and Environmental Engineering, Royal Institute of Technology, Stockholm, 2011.

King, G. and Zeng, L.: Logistic Regression in Rare Events Data, Polit. Anal., 9, 137-163, https://doi.org/10.1093/oxfordjournals.pan.a004868, 2001.

Klok, E. J., Jasper, K., Roelofsma, K. P., Gurtz, J., and Badoux, A.: Distributed hydrological modelling of a heavily glaciated Alpine river basin, Hydrol. Sci. J., 46, 553-570, https://doi.org/10.1080/02626660109492850, 2001.

Konzelmann, T., van de Wal, R. S. W., Greuell, W., Bintanja, R., Henneken, E. A. C., and Abe-Ouchi, A.: Parameterization of global and longwave incoming radiation for the Greenland Ice Sheet, Glob. Planet. Change, 9, 143-164, https://doi.org/10.1016/0921-8181(94)90013-2, 1994.

Krøgli, I. K., Devoli, G., Colleuille, H., Boje, S., Sund, M., and Engen, I. K.: The Norwegian forecasting and warning service for rainfall- and snowmelt-induced landslides, Nat. Hazards Earth Syst. Sci., 18, 1427-1450, https://doi.org/10.5194/nhess18-1427-2018, 2018.

Lindroth, A.: Canopy Conductance of Coniferous Forests Related to Climate, Water Resour. Res., 21, 297-304, https://doi.org/10.1029/WR021i003p00297, 1985.

Liu, Z. and Todini, E.: Towards a comprehensive physically-based rainfall-runoff model, Hydrol. Earth Syst. Sci., 6, 859-881, https://doi.org/10.5194/hess-6-859-2002, 2002.

Lohammar, T., Larsson, S., Linder, S., and Falk, S. O.: FAST - simulation medels of gaseous exchange in Scots pine, in: Structure and Function of Northern Coniferous Forests - An Ecosystem 
Study, edited by: Persson, T., 505-523, Oikos Editorial Office, Stockholm, 1980.

Van Looy, K., Bouma, J., Herbst, M., Koestel, J., Minasny, B., Mishra, U., Montzka, C., Nemes, A., Pachepsky, Y. A., Padarian, J., Schaap, M. G., Tóth, B., Verhoef, A., Vanderborght, J., van der Ploeg, M. J., Weihermüller, L., Zacharias, S., Zhang, Y., and Vereecken, H.: Pedotransfer Functions in Earth System Science: Challenges and Perspectives, Rev. Geophys., 55, 11991256, https://doi.org/10.1002/2017RG000581, 2017.

Madani, E. M. H., Jansson, P. E., and Babelon, I.: Differences in water balance between grassland and forest watersheds using longterm data, derived using the CoupModel, Hydrol. Res., 49, 7289, https://doi.org/10.2166/nh.2017.154, 2018.

Marino, P., Santonastaso, G. F., Fan, X., and Greco, R.: Prediction of shallow landslides in pyroclastic-covered slopes by coupled modeling of unsaturated and saturated groundwater flow, Landslides, 18, 31-41, https://doi.org/10.1007/s10346-020-01484-6, 2020.

Martelloni, G., Segoni, S., Fanti, R., and Catani, F.: Rainfall thresholds for the forecasting of landslide occurrence at regional scale, Landslides, 9, 485-495, https://doi.org/10.1007/s10346011-0308-2, 2012.

Menzel, L., Lang, H., and Rohmann, M.: Mittlere jährliche aktuelle Verdunstungshöhen 1973-1992, in: Hydrologischer Atlas der Schweiz, edited by: Spreafico, M., EDMZ, Bern, 1999.

Mirus, B., Morphew, M., and Smith, J.: Developing Hydro-Meteorological Thresholds for Shallow Landslide Initiation and Early Warning, Water, 10, 1274, https://doi.org/10.3390/w10091274, 2018a.

Mirus, B. B., Becker, R. E., Baum, R. L., and Smith, J. B.: Integrating real-time subsurface hydrologic monitoring with empirical rainfall thresholds to improve landslide early warning, Landslides, 1-11, 1909-1919, https://doi.org/10.1007/s10346018-0995-z, 2018b.

Monteith, J. L.: Evaporation and Environment, Symposia of the Society for Experimental Biology, 19, 205-234, 1965.

Mualem, Y.: A new model for predicting the hydraulic conductivity of unsaturated porous media, Water Resour. Res., 12, 513-522, https://doi.org/10.1029/WR012i003p00513, 1976.

Okkonen, J., Ala-Aho, P., Hänninen, P., Hayashi, M., Sutinen, R., and Liwata, P.: Multi-year simulation and model calibration of soil moisture and temperature profiles in till soil, Eur. J. Soil Sci., 68, 829-839, https://doi.org/10.1111/ejss.12489, 2017.

Or, D.: The Tyranny of Small Scales - On Representing Soil Processes in Global Land Surface Models, Water Resour. Res., 56, https://doi.org/10.1029/2019wr024846, 2020.

Orland, E., Roering, J. J., Thomas, M. A., and Mirus, B. B.: Deep Learning as a tool to forecast hydrologic response for landslide-prone hillslopes, Geophys. Res. Lett., 47, https://doi.org/10.1029/2020GL088731, 2020.

Paniconi, C. and Putti, M.: Physically based modeling in catchment hydrology at 50: Survey and outlook, Water Resour. Res., 51, 7090-7129, https://doi.org/10.1002/2015WR017780, 2015.

Pellet, C. and Hauck, C.: Monitoring soil moisture from middle to high elevation in Switzerland: set-up and first results from the SOMOMOUNT network, Hydrol. Earth Syst. Sci., 21, 3199 3220, https://doi.org/10.5194/hess-21-3199-2017, 2017.

Pellet, C., Hilbich, C., Marmy, A., and Hauck, C.: Soil Moisture Data for the Validation of Permafrost Models Using Direct and
Indirect Measurement Approaches at Three Alpine Sites, Front Earth Sci., 3, 1-21, https://doi.org/10.3389/feart.2015.00091, 2016.

Piciullo, L., Calvello, M., and Cepeda, J. M.: Territorial early warning systems for rainfall-induced landslides, Earth-Sci. Rev., 179, 228-247, https://doi.org/10.1016/j.earscirev.2018.02.013, 2018.

Piciullo, L., Tiranti, D., Pecoraro, G., Cepeda, J. M., and Calvello, M.: Standards for the performance assessment of territorial landslide early warning systems, Landslides, 17, 2533-2546, https://doi.org/10.1007/s10346-020-01486-4, 2020.

Pollock, W. and Wartman, J.: Human Vulnerability to Landslides, GeoHealth, 4, 1-17, https://doi.org/10.1029/2020gh000287, 2020.

Ponziani, F., Pandolfo, C., Stelluti, M., Berni, N., Brocca, L., and Moramarco, T.: Assessment of rainfall thresholds and soil moisture modeling for operational hydrogeological risk prevention in the Umbria region (central Italy), Landslides, 9, 229-237, https://doi.org/10.1007/s10346-011-0287-3, 2012.

Posner, A. J. and Georgakakos, K. P.: Soil moisture and precipitation thresholds for real-time landslide prediction in El Salvador, Landslides, 12, 1179-1196, https://doi.org/10.1007/s10346-0150618-x, 2015.

Rebetez, M., von Arx, G., Gessler, A., Pannatier, E. G., Innes, J. L., Jakob, P., Jetel, M., Kube, M., Nötzli, M., Schaub, M., Schmitt, M., Sutter, F., Thimonier, A., Waldner, P., and Haeni, M.: Meteorological data series from Swiss long-term forest ecosystem research plots since 1997, Ann. For. Sci., 75, https://doi.org/10.1007/s13595-018-0709-7, 2018.

Reichle, R. H., De Lannoy, G. J. M., Forman, B. A., Draper, C. S., and Liu, Q.: Connecting Satellite Observations with Water Cycle Variables Through Land Data Assimilation: Examples Using the NASA GEOS-5 LDAS, Surv. Geophys., 35, 577-606, https://doi.org/10.1007/s10712-013-9220-8, 2014.

Reichle, R. H., De Lannoy, G. J. M., Liu, Q., Ardizzone, J. V., Colliander, A., Conaty, A., Crow, W., Jackson, T. J., Jones, L. A., Kimball, J. S., Koster, R. D., Mahanama, S. P., Smith, E. B., Berg, A., Bircher, S., Bosch, D., Caldwell, T. G., Cosh, M., González-Zamora, Á., Collins, C. D. H., Jensen, K. H., Livingston, S., Lopez-Baeza, E., Martínez-Fernández, J., McNairn, H., Moghaddam, M., Pacheco, A., Pellarin, T., Prueger, J., Rowlandson, T., Seyfried, M., Starks, P., Su, Z., Thibeault, M., van der Velde, R., Walker, J., Wu, X., and Zeng, Y.: Assessment of the SMAP Level-4 surface and root-zone soil moisture product using in situ measurements, J. Hydrometeorol., 18, 2621-2645, https://doi.org/10.1175/JHM-D-17-0063.1, 2017.

Richards, L. A.: Capillary conduction of liquids through porous mediums, J. Appl. Phys., 1, 318-333, https://doi.org/10.1063/1.1745010, 1931.

Schaap, M. G., Leij, F. J., and van Genuchten, M. T.: ROSETTA: a computer program for estimating soil hydraulic parameters with hierarchical pedotransfer functions, J. Hydrol., 251, 163-176, https://doi.org/10.1016/S0022-1694(01)00466-8, 2001.

Scherler, M., Hauck, C., Hoelzle, M., Stähli, M., and Völksch, I.: Meltwater infiltration into the frozen active layer at an alpine permafrost site, Permafr. Periglac. Process., 21, 325-334, https://doi.org/10.1002/ppp.694, 2010.

Schmid, F., Fraefel, M., and Hegg, C.: Unwetterschäden in der Schweiz 1972-2002: Verteilung, Ursachen, Entwicklung, Wasser Energie Luft, 96, 21-28, 2004. 
Segoni, S., Piciullo, L., and Gariano, S. L.: A review of the recent literature on rainfall thresholds for landslide occurrence, Landslides, 15, 1483-1501, https://doi.org/10.1007/s10346-0180966-4, 2018a.

Segoni, S., Rosi, A., Lagomarsino, D., Fanti, R., and Casagli, N.: Brief communication: Using averaged soil moisture estimates to improve the performances of a regional-scale landslide early warning system, Nat. Hazards Earth Syst. Sci., 18, 807-812, https://doi.org/10.5194/nhess-18-807-2018, 2018 b.

Šimůnek, J., van Genuchten, M. T., and Šejna, M.: HYDRUS: Model Use, Calibration, and Validation, Trans. ASABE, 55, 1263-1276, https://doi.org/10.13031/2013.42239, 2012.

Stähli, M., Sättele, M., Huggel, C., McArdell, B. W., Lehmann, P., Van Herwijnen, A., Berne, A., Schleiss, M., Ferrari, A., Kos, A., Or, D., and Springman, S. M.: Monitoring and prediction in early warning systems for rapid mass movements, Nat. Hazards Earth Syst. Sci., 15, 905-917, https://doi.org/10.5194/nhess-15905-2015, 2015.

Terlien, M. T. J.: The determination of statistical and deterministic hydrological landslide-triggering thresholds, Environ. Geol., 35, 124-130, https://doi.org/10.1007/s002540050299, 1998.

Terzaghi, K.: Theoretical Soil Mechanics, John Wiley \& Sons, Inc., Hoboken, NJ, USA, 1943.

Thomas, M. A., Mirus, B. B., Collins, B. D., Lu, N., and Godt, J. W.: Variability in soil-water retention properties and implications for physics-based simulation of landslide early warning criteria, Landslides, 15, 1265-1277, https://doi.org/10.1007/s10346-0180950-z, 2018.

Thomas, M. A., Collins, B. D., and Mirus, B. B.: Assessing the Feasibility of Satellite-Based Thresholds for Hydrologically Driven Landsliding, Water Resour. Res., 55, 9006-9023, https://doi.org/10.1029/2019WR025577, 2019.

Thomas, M. A., Mirus, B. B., and Smith, J. B.: Hillslopes in humidtropical climates aren't always wet: Implications for hydrologic response and landslide initiation in Puerto Rico, Hydrol. Process., 34, 4307-4318, https://doi.org/10.1002/hyp.13885, 2020.

Topp, G. C., Davis, J. L., and Annan, A. P.: Electromagnetic determination of soil water content: Measurements in coaxial transmission lines, Water Resour. Res., 16, 574-582, https://doi.org/10.1029/WR016i003p00574, 1980.

van Genuchten, M. T.: A Closed-form Equation for Predicting the Hydraulic Conductivity of Unsaturated Soils, Soil Sci. Soc. Am. J., 44, 892-898, https://doi.org/10.2136/sssaj1980.03615995004400050002x, 1980.

van Genuchten, M. T.: A Numerical Model for Water and Solute Movement in and Below the Root Zone, Riverside, California, United States Department of Agriculture, 1987.

Varnes, D. J.: Slope Movement Types and Processes, in: Landslides, Analysis and Control, Special Report 176, edited by: Schuster, R. L. and Krizek, R. J., 11-33, Transportation Research Board, National Academy of Sciences, Washington D.C., 1978.
Viviroli, D., Zappa, M., Gurtz, J., and Weingartner, R.: An introduction to the hydrological modelling system PREVAH and its preand post-processing-tools, Environ. Model. Softw., 24, 12091222, https://doi.org/10.1016/j.envsoft.2009.04.001, 2009.

Walthert, L., Scherler, M., Stähli, M., Huber, M., Baltensweiler, A., and Papritz, L. A.: Böden und Wasserhaushalt von Wäldern und Waldstandorten der Schweiz unter heutigem und zukünftigem Klima (BOWA-CH) Schlussbericht des Projektes, ETH Zurich, Zurich, 2015.

Wicki, A., Lehmann, P., Hauck, C., Seneviratne, S. I., Waldner, P., and Stähli, M.: Assessing the potential of soil moisture measurements for regional landslide early warning, Landslides, 17, 1881-1896, https://doi.org/10.1007/s10346-020-01400-y, 2020.

Wieczorek, G. F.: Landslide Triggering Mechanisms, in: Landslides investigation and mitigation, edited by: Turner, A. K. and Schuster, R. L., p. 673, National Academy Press, Washington, D.C., 1996.

Wu, M., Zhao, Q., Jansson, P.-E., Wu, J., Tan, X., Duan, Z., Wang, K., Chen, P., Zheng, M., Huang, J., and Zhang, W.: Improved soil hydrological modeling with the implementation of salt-induced freezing point depression in CoupModel: Model calibration and validation, J. Hydrol., 596, 125693, https://doi.org/10.1016/j.jhydrol.2020.125693, 2020.

Wu, S. H. and Jansson, P.-E.: Modelling soil temperature and moisture and corresponding seasonality of photosynthesis and transpiration in a boreal spruce ecosystem, Hydrol. Earth Syst. Sci., 17, 735-749, https://doi.org/10.5194/hess-17-735-2013, 2013.

Zhang, Y. and Schaap, M. G.: Weighted recalibration of the Rosetta pedotransfer model with improved estimates of hydraulic parameter distributions and summary statistics (Rosetta3), J. Hydrol., 547, 39-53, https://doi.org/10.1016/j.jhydrol.2017.01.004, 2017.

Zhang, Y. and Schaap, M. G.: Estimation of saturated hydraulic conductivity with pedotransfer functions: A review, J. Hydrol., 575, 1011-1030, https://doi.org/10.1016/j.jhydrol.2019.05.058, 2019.

Zhao, B., Dai, Q., Han, D., Zhang, J., Zhuo, L., and Berti, M.: Application of hydrological model simulations in landslide predictions, Landslides, 17, 877-891, https://doi.org/10.1007/s10346019-01296-3, 2019a.

Zhao, B., Dai, Q., Han, D., Dai, H., Mao, J., and Zhuo, L.: Probabilistic thresholds for landslides warning by integrating soil moisture conditions with rainfall thresholds, J. Hydrol., 574, 276-287, https://doi.org/10.1016/j.jhydrol.2019.04.062, $2019 \mathrm{~b}$.

Zhuo, L., Dai, Q., Han, D., Chen, N., and Zhao, B.: Assessment of simulated soil moisture from WRF Noah, Noah-MP, and CLM land surface schemes for landslide hazard application, Hydrol. Earth Syst. Sci., 23, 4199-4218, https://doi.org/10.5194/hess-234199-2019, 2019a.

Zhuo, L., Dai, Q., Han, D., Chen, N., Zhao, B., and Berti, M.: Evaluation of Remotely Sensed Soil Moisture for Landslide Hazard Assessment, IEEE J. Sel. Top. Appl. Earth Obs. Remote Sens., 12, 162-173, https://doi.org/10.1109/JSTARS.2018.2883361, 2019b. 